\title{
ROLE OF SILICA FUME IN COMPRESSIVE STRENGTH OF CEMENT PASTE, MORTAR, AND CONCRETE
}

\author{
B Y \\ XIAOFENG CONG \\ SHANGLONG GONG \\ DAVID DARWIN \\ STEVEN L. MCCABE
}

\begin{abstract}
A Report on Research Sponsored by
THE UNIVERSITY OF KANSAS

STRUCTURAL ENGINEERING \& MATERIALS LABORATORY
\end{abstract}

UNIVERSITY OF KANSAS

LAWRENCE, KANSAS

APRIL 1990 


\title{
ROLE OF SILICA FUME IN COMPRESSIVE STRENGTH OF CEMENT PASTE, MORTAR, AND CONCRETE
}

\begin{abstract}
Controversy exists as to why silica fume increases the strength of concrete when it is used as a partial replacement for cement. Some evidence supports the view that the increase in strength is due to an increase in the strength of the cement paste constituent of concrete. However, contradictory evidence exists that shows no increase in the strength of cement paste, but substantial increases in concrete strength, when silica fume is used. The latter evidence is used to support the theory that silica fume strengthens concrete by strengthening the bond between cement paste and aggregate.

This study is designed to explain the contradictory evidence and establish the role played by silica fume in controlling the strength of concrete and its constituent materials. These goals are accomplished using cement pastes, mortars, and concretes with water-cementitious material ratios ranging from 0.30 to 0.39 . Mixtures incorporate no admixtures, a superplasticizer only, or silica fume and a superplasticizer. The research demonstrates that replacement of cement by silica fume and the addition of a superplasticizer increases the strength of cement paste. It also demonstrates that cement paste specimens, with or without silica fume, can exhibit reduced strength compared to other specimens with the same water-cementitious material ratio if the material segregates during fabrication, thus explaining some earlier experimental observations. The segregation of cement paste is caused by high superplasticizer dosages that do not cause segregation of concrete with the same water-cementitious material ratio. Concrete containing silica fume as a partial replacement for cement exhibits an increased compressive strength because of the improved strength of its cement paste constituent. Changes in the paste-aggregate interface caused by silica fume appear to have little effect on the uniaxial compressive strength of concrete.
\end{abstract}




\section{INTRODUCTION}

It is well recognized that the use of silica fume as a partial replacement for cement provides a significant increase in the strength of concrete. There is, however, controversy as to what causes the increase in strength. Some researchers believe that the increase in strength is primarily the result of a higher quality cement paste matrix, while others feel sure that the increase in concrete strength is the result of a greatly improved bond strength between the cement paste and the aggregate.

There is strong evidence that silica fume increases the homogeneity and decreases the number of large pores in cement paste (Mehta and Gjorv 1982, Feldman and Huang 1985), both of which would lead to a higher strength material. Work by Darwin, Shen, and Harsh (1988) with cement paste and mortar, supports the importance of the quality of the paste in controlling concrete strength.

There is also ample evidence that the use of silica fume results in a denser interface between cement paste and coarse aggregate (Regourd 1985, Bentur and Cohen 1987, Bentur, Goldman and Cohen 1988). Some researchers have offered indirect evidence indicating that the strength increase that occurs with the addition of silica fume to concrete is the result of an increase in bond strength between hydrated cement paste and aggregate (Huang and Feldman 1985, Rosenberg and Gaidis 1989, 1990, Goldman and Bentur 1989). Rosenberg and Gaidis (1989) and Goldman and Bentur (1989) have gone on record as stating that the enhancement in concrete strength obtained by the addition of silica fume is due primarily to the increased bond strength between hydration products and coarse aggregate. Goldman and Bentur (1989) feel that the higher bond strength causes the aggregate to act as a "reinforcing filler." Clearly, general agreement does not exist on the mechanism by which silica fume increases the strength of concrete.

In light of the ongoing controversy, this report describes work that is aimed at improving the understanding of the role played by silica fume in concrete, and attempts to explain some of the apparently conflicting results from earlier studies. 


\section{BACKGROUND}

The role of the cement paste-aggregate interface on the behavior of mortar and concrete is central to the current discussion. The topic has been under study for many years. Some experimental work (Shah and Chandra 1968, Nepper-Christensen and Nielsen 1969) indicates that the interface plays a major role in concrete strength. These studies, however, used relatively thick, soft coatings on coarse aggregate to reduce bond strength. These coatings essentially isolated the aggregate from the surrounding mortar. The effect was similar to inducing a large number of voids in the concrete.

Other studies (Darwin and Slate 1970, Perry and Gillott 1977) established that a major reduction in interfacial bond strength between cement paste and coarse aggregate has relatively little effect on initial stiffness, and may result in a 10 percent reduction in compressive strength. Finite element studies by Maher and Darwin (1977) substantiate these experimental results.

More recently, Popovics (1987) attempted to increase the compressive strength of concrete by increasing interfacial bond strength through the application of various surface treatments to the coarse aggregate. He achieved an improvement in compressive strength in a few cases. However, in most cases, the surface treatments caused a reduction in compressive strength.

Studies by Huang and Feldman (1985), Bentur et al. (1988), Rosenberg and Gaidis (1989), and Goldman and Bentur (1989) seem, once again, to emphasize the importance of interfacial bond strength for concretes in which silica fume is used as a partial replacement for cement. Huang and Feldman (1985) found that mortar without silica fume had a lower strength than cement paste with the same water-cement ratio, while mortar with 30 percent of the cement replaced by silica fume had a higher strength than a cement-silica fume paste with the same water-cementitious material ratio. They concluded that the higher strength mortar must be due to improved bond strength between paste and sand and that the improved bond was due to the conversion of calcium hydroxide, which normally forms preferentially at the surface of aggregate particles, to calcium 
silicate hydrate due to the presence of reactive silica. Rosenberg and Gaidis (1989), Bentur et al. (1988), and Goldman and Bentur (1989) made similar observations for concrete. These investigators observed no increase in the strength of cement paste (at water-cementitious ratios of 0.24 and 0.33 for Rosenberg and Bentur, respectively) due to the addition of silica fume and superplasticizer, but did observe substantial increases in the strength of concrete made with the same materials. The researchers reasoned that the increase in the strength of the concrete was due to an improved interfacial bond strength between cement paste and aggregate.

While the reasoning in these cases seems straightforward, there were significant weaknesses in each of the experiments. Huang and Feldman (1985) added a superplasticizer to the mortar containing silica fume, but not to the cement paste containing silica fume. Thus, their results may be used to conclude that the increase in compressive strength of mortar relative to cement paste was due to the addition of the superplasticizer rather than the presence of silica fume. Bentur and coworkers (Bentur et al. 1988, Goldman and Bentur 1989) used different amounts of superplasticizer in the concretes and cement pastes as a function of the percent of cement replaced by silica fume. They selected the amount of superplasticizer based on the "maximum that could be incorporated" in concrete "without causing separation of the fresh mix." The result was a 55 percent increase in superplasticizer for the concretes and pastes with a 15 percent replacement of cement by silica fume compared to the materials without silica fume. This substantial increase in superplasticizer for mixtures containing silica fume raises a question: Could the greater amount of superplasticizer have adversely affected the degree of segregation and bleeding in the cement paste specimens, causing a reduction in strength, while not adversely affecting the concrete? This point will be directly addressed in this study.

In contrast to the observations cited above, Darwin et al. (1988) found that the strengths of both cement paste and mortar were increased with a 15 percent replacement of cement by silica fume. However, the ratio of the strength of mortar to the strength of cement paste was lower for the materials containing silica fume. Using the line of reasoning offered by Huang and Feldman 
(1985), Rosenberg and Gaidis (1989), and Goldman and Bentur (1989), it might be concluded that the bond strength between the cement paste and sand was actually lower when silica fume was used. Thus the results appear to be contradictory. Who is correct? Is there an error in reasoning somewhere? The current study is designed to answer these questions and explain what appear to be conflicting results.

\section{EXPERIMENTAL WORK}

Cement pastes, mortars, and concretes with water-cementitious material ratios by weight, w/c, ranging from 0.30 to 0.39 were used. Mixtures incorporated no admixtures, superplasticizer only, or silica fume and superplasticizer, designated as NA, SP and SF, respectively. The goals of this study include (1) determining under what conditions silica fume, in conjunction with a superplasticizer, increases the strength of cement paste when it is used as a partial replacement for cement and (2) determining the degree of strength improvement in mortar and concrete obtained with the addition of silica fume and a superplasticizer. NA and SP pastes and mortars have w/c = $0.30,0.33,0.36$, and 0.39 . SF pastes and mortars include $w / c=0.33,0.36$, and 0.39 . $w / c=$ 0.30 was not used for SF paste and mortar due to stickiness of the materials. Concretes for each combination of cementitious materials have $w / c=0.33$ and 0.39 . The liquid portion of the superplasticizer was counted as part of the mixing water.

\section{Materials}

Ash Grove Type I portland cement with a $C_{3} S$ content of 45 percent, a $C_{2} S$ content of 29 percent, a $\mathrm{C}_{3} \mathrm{~A}$ content of 7 percent, and a $\mathrm{C}_{4} \mathrm{AF}$ content of 9 percent was used. The silica fume used in the study was in powder form and contained 95 percent $\mathrm{SiO}_{2}, 0.39$ percent $\mathrm{CaO}, 0.21$ percent $\mathrm{MgO}, 0.11$ percent $\mathrm{K}_{2} \mathrm{O}, 0.15$ percent $\mathrm{Na}_{2} \mathrm{O}, 0.13$ percent $\mathrm{Al}_{2} \mathrm{O}_{3}, 0.40$ percent $\mathrm{Fe}_{2} \mathrm{O}_{3}$, and had 2.46 percent loss on ignition.

The fine aggregate was Kansas river sand consisting mainly of quartz, with about 10 per- 
cent feldspar; fineness modulus $=2.60 ;$ bulk specific gravity (saturated surface dry) $=2.62 ; a b-$ sorption (dry) $=0.5$ percent. The sand was passed through a No. 4 sieve. The coarse aggregate was a $3 / 4$ in. maximum size crushed limestone with bulk specific gravity (saturated surface dry) $=$ 2.54 ; and absorption (dry) $=3.5$ percent. The coarse aggregate was passed through a $3 / 4$ in. sieve and retained on a No. 8 sieve.

The superplasticizer was Master Builders Rheobuild 1000, a calcium napthalene sulfonate condensate-based superplasticizer. The material has a specific gravity of 1.205 and is 40 percent solids by weight. It was used at the rate of 15 fluid ounces per $100 \mathrm{lbs}$ of cementitious material (15 oz/cwt) for the SP test specimens and for the majority of the SF test specimens. To evaluate the effect of increased amounts of superplasticizer on the strength of SF materials, additional mixtures of cement paste and concrete containing silica fume with $w / c=0.33$ were made using 25 $\mathrm{oz} / \mathrm{cwt}$, the upper recommended limit, and $30 \mathrm{oz} / \mathrm{cwt}, 20$ percent above the maximum recommended dosage.

Mixtures were proportioned to limit the number of variables in the study. The cement pastes represented the paste constituents of the mortars, and the mortars represented the mortar constituents of the concretes. All mortars contained the same volume fractions of cement paste (56 percent) and sand (44 percent), while all concretes contained the same volume fractions of mortar (68 percent) and coarse aggregate (32 percent). Mixture compositions are summarized in Table 1. These mixture proportions produced concretes with slumps of 1 inch or less, with the exception of the SP concrete with $w / c=0.39$ (slump $=71 / 2$ in.) and the SF concrete with $w / c=0.33$ and 30 $\mathrm{oz} / \mathrm{cwt}$ of superplasticizer (slump $=51 / 2$ in.).

\section{Test Specimens}

As fabricated, the test specimens were 1 in. square by 5 in. long for cement paste and mortar, and $3 \mathrm{in.} \mathrm{square} \mathrm{by} 12 \mathrm{in.} \mathrm{long} \mathrm{for} \mathrm{concrete.} \mathrm{The} \mathrm{sand} \mathrm{and} \mathrm{coarse} \mathrm{aggregate} \mathrm{were} \mathrm{oven} \mathrm{dried} \mathrm{at}$ $105^{\circ} \mathrm{C}$ for 24 hours prior to batching. The aggregates were then cooled to room temperature. 
Sand and coarse aggregate were soaked in part of the mix water for 2 and 7 minutes, respectively, prior to the start of the mixing operations. Batch water was increased to account for the absorption of the aggregates. Cement paste and mortar specimens were mixed according to ASTM C 305, except that the sand was pre-soaked, the final 20 percent of the water and all of the superplasticizer were added after the first mixing period with cement, and the mixing time was doubled to obtain better dispersion of the materials. Concrete specimens were batched and mixed by hand following the sequence prescribed in ASTM C 305, but doubling the mixing and resting time periods and holding 20 percent of the water and the superplasticizer, as done for paste and mortar.

Specimens were cast vertically in groups of 6 . The molds were oiled prior to casting, and the joints were sealed with modeling clay to prevent a loss of moisture. The molds were filled in three equal lifts. For paste and mortar, each layer was hand rodded 25 times using a $1 / 4 \mathrm{in}$. diameter steel rod and then consolidated on a vibrating table with a frequency of $60 \mathrm{cycles} / \mathrm{sec}$ and an amplitude of $0.006 \mathrm{in}$. Each layer was vibrated for $11 / 2$ to $21 / 2$ minutes (NA paste and SP mor$\operatorname{tar} 11 / 2$ min., SF paste and NA mortar 2 min., SF mortar $21 / 2$ min.), depending on workability, except for the SP paste specimens, which required no vibration. An extra batch of SP paste $(\mathrm{w} / \mathrm{c}=$ 0.33) was vibrated for 2 minutes to check for positive or negative effects of consolidation on the strength of this highly fluid paste. As will be seen, no effect was found. Concrete specimens were filled in three layers. The concrete specimens with a slump of $1 \mathrm{in}$. or more with were consolidated by rodding, while the other concretes were consolidated using a $3 / 4$ in. internal hand-held vibrator (NA concrete $1 / 2 \mathrm{~min}$., SF concrete $1 \mathrm{~min}$.). After consolidation, the molds were sealed at the top.

During the first 24 hours, the molds were stored in the laboratory in a horizontal position to reduce the effects of bleeding. Specimens were then removed from the molds and stored in limesaturated water until the time of test.

Prior to testing, cement paste and mortar specimens were shortened to 3 in. and concrete specimens were shortened to $9 \mathrm{in}$. by removing equal portions from each end using a high-speed 
masonry saw. The 3 to 1 aspect ratio of the specimens greatly reduces the effects of end conditions during testing, which dominate the stresses in the traditional cube specimen and in much of the volume of standard concrete cylinders with 2 to 1 aspect ratios. Because of end restraint, cubes and the end regions of all specimens are placed in triaxial rather than uniaxial compression. In the current study, special care was taken to keep the sawed surfaces square with the length of the specimen.

A layer of high strength gypsum cement (Hydrostone) was placed on the ends of the specimens. A smooth piece of glass was used to limit the cap thickness to $0.02 \mathrm{in}$. The capping material was allowed to dry for at least 30 minutes before testing. Each specimen was wrapped in plastic to avoid the loss of moisture during testing.

Specimens were tested in compression using a hydraulic tester at ages of 3,7 , and 28 days, using spherically seated upper bearing blocks (ASTM C 39 and C 109). The load-head speed was set to produce a stress rate of 35 psi per sec for loads up to one-half of the ultimate. This loadhead speed was maintained for higher stresses, in accordance with ASTM C 39.

\section{Results}

Average specimen strengths are summarized in Table 2 and Figs. 1 through 5. Each value represents the average of two test specimens. Individual test results are presented in Appendix A. Figs. 1 and 2 compare the strengths of cement pastes with water-cementitious material ratios ranging from 0.30 to 0.39 at ages of 3,7 and 28 days. Regardless of water-cementitious material ratio, the SF cement paste with a superplasticizer dosage rate of $15 \mathrm{oz} / \mathrm{cwt}$ (taken as the standard) exhibits the highest strength at all ages, while the SP cement paste exhibits the lowest strength. These results are in sharp contrast with those of Goldman and Bentur (1989) and Rosenberg and Gaidis (1990) who obtained no additional strength for cement paste due to the replacement of cement by silica fume. The strengths of the different mixtures are closest at 3 days. The mixtures containing silica fume become increasingly stronger relative to the other two mixtures with 
increasing time. The SP pastes are weaker than the NA pastes, but the difference in relative strength between the two materials is not consistent for different water-cement ratios with increasing time. From 7 to 28 days, the absolute difference in strength between NA and SP pastes is nearly constant for $w / c=0.30$, decreases for $w / c=0.33$ and 0.36 , and increases for $w / c=$ 0.39 .

Figs. 3 and 4 compare the strengths of the mortars at ages of 3,7 and 28 days. The trends differ from those observed for cement paste. At 3 days, the SF mortar is the weakest of the three mixtures at each w/c, while the SP mortar is the strongest. However, at later ages, the SF mortar is the strongest mixture at each w/c. The strengths of the NA and SF mortars are very close, but NA mortar is consistently the weaker, except for $w / c=0.39$ at 28 days.

Fig. 5 compares the strengths of the concretes with $w / c=0.33$ and 0.39 at 3,7 , and 28 days. At 3 days, the SP concretes are the strongest, while the SF concretes are the weakest. At 7 days, the strengths of the three concretes are nearly equal at both w/c's. At 28 days, the SF concretes are the strongest, while the other two concretes are very close in strength.

Fig. 6 compares the strengths of the SF pastes and concretes made with 25 oz/cwt and 30 $\mathrm{oz} / \mathrm{cwt}$ of superplasticizer to the other pastes and concretes with $w / \mathrm{c}=0.33$. At 28 days, the 25 oz/cwt SF paste is considerably weaker (12380 psi) than the $15 \mathrm{oz} / \mathrm{cwt}$ SF paste (16020 psi) and very close in strength to the NA paste (12560 psi). However, the $25 \mathrm{oz} / \mathrm{cwt}$ SF concrete is stronger than all other concretes tested ( $8990 \mathrm{psi})$. The $30 \mathrm{oz} / \mathrm{cwt}$ SF paste is the weakest of the 0.33 w/c pastes (11150 psi at 28 days), while the $30 \mathrm{oz} / \mathrm{cwt}$ SF concrete ( $8170 \mathrm{psi})$ is weaker than the $25 \mathrm{oz} / \mathrm{cwt}$ SF concrete, but slightly stronger than the $15 \mathrm{oz} / \mathrm{cwt}$ SF concrete (8080 psi).

Finally, the vibrated and non-vibrated (standard) 0.33 SP pastes have virtually identical strengths (11550 psi for the vibrated past versus 11640 psi for the non-vibrated paste at 28 days) showing that the consolidation technique had no effect on the strength of this material. 


\section{DISCUSSION}

\section{Strength}

The results illustrated in Figs. 1-5 suggest several things about the roles played by superplasticizer and silica fume.

Superplasticizers break up flocs of cement particles. This releases water that improves workability and provides for better access of water to the cement particles, which results in a greater degree of hydration and a higher strength. The lower strength exhibited by the SP pastes probably is due to the greater fluidity and accompanying segregation and bleeding that occur in these mixtures. The specimens were stored in a horizontal position to reduce the overall effects of bleeding. However, due to segregation, the highly fluid SP pastes have an increased water content (a difference in evaporatable water alone of 1 percent at 1 day compared to less than 0.1 percent for the $15 \mathrm{oz} / \mathrm{cwt} \mathrm{SF}$ paste), and are thus weaker, on the upper side. This variation of properties within the cross section results in a reduced compressive strength for the SP paste specimens.

Silica fume with $15 \mathrm{oz} / \mathrm{cwt}$ of superplasticizer provides a consistently higher strength cement paste at all ages, although the difference is smallest at 3 days. There are two reasons for the higher strength of these SF pastes. First, because of its small particle size, silica fume can act as a filler for the spaces between cement grains. This results in a reduction in the size of the individual pores and voids in the paste, although the total porosity is not affected (Feldman and Huang 1985). Since pores are discontinuities in the cement paste matrix, reduced pore sizes require a higher stress to initiate a crack; thus the strength is increased. The filler effect is illustrated by the work of Detwiler and Mehta (1989). In their tests, carbon black, which is physically similar to silica fume but is not pozzolanic, was used to replace silica fume (10 percent of cement by weight) in concrete. Their tests show that the concrete containing carbon black obtained a comparable strength to that containing silica fume at early ages, even though the total cement content was 10 percent below that of plain cement concrete.

A second reason for the high strength of the SF paste is due to the pozzolanic nature of 
silica fume, which also explains why the SF pastes become progressively stronger with time relative to the NA and SP pastes. The pozzolanic reaction is slower than normal cement hydration, but continues over time. As more calcium hydroxide is converted to calcium silicate hydrate, the strength of the material will continue to increase.

In contrast to the SP pastes, which are weaker than the NA pastes (Figs. 1 and 2), the SP mortars generally have a higher strength than the NA mortars (Figs. 3 and 4). The higher strength of the SP mortar is probably due to the greater early hydration obtained due to better dispersion of the cement particles. The addition of sand greatly reduces bleeding which causes the reduced strength for the SP pastes.

The SF mortars consistently exhibit a lower compressive strength at 3 days and higher strengths at 7 and 28 days than the NA and SP mortars. The relative rate of strength gain of the SF mortars shown in Figs. 3 and 4 matches that seen for the SF pastes and is probably due to the pozzolanic effect (Detwiler and Mehta 1989). The consistently lower initial strength of the SF mortars and the relatively narrow strength range of the mortars, compared to the pastes, suggests that the presence of an aggregate has a more disruptive effect on the strength of SF paste than on NA or SP pastes. This observation also applies to the concrete strength results (Fig. 5).

The results illustrated in Fig. 6 show why Goldman and Bentur (1989) obtained no increase in strength in cement paste but got a sizeable increase in strength for concrete when they replaced up to 15 percent of the cement with silica fume. In the current study, the SF pastes $(w / c=$ 0.33 ) with 25 and 30 fluid ounces of superplasticizer per $100 \mathrm{lb}$. of cementitious material are weaker than the $15 \mathrm{oz} / \mathrm{cwt} \mathrm{SF}$ paste. Both pastes are also weaker than the NA paste, and the 30 oz/cwt SF paste is weaker than the SP paste. The lower strength of the SF pastes with increased dosages of superplasticizer is due, at least in part, to the greater segregation exhibited by the more fluid materials (note a check for evaporatable water showed a difference of 0.5 percent for the 30 oz/cwt SF paste). On the other hand, the greater amount of superplasticizer enhanced the workability of the $25 \mathrm{oz} / \mathrm{cwt}$ SF concrete with no adverse affect on segregation and produced the 
highest strength concrete in this study. The $30 \mathrm{oz} / \mathrm{cwt}$ SF concrete, though weaker than the 25 oz/cwt concrete, produced the next highest 28-day strength. This occurred in spite of the fact that the dosage rate was 20 percent above the recommended maximum, likely resulting in some retardation of hydration.

Clearly, the strength of both cement paste and concrete can be affected by the dosage of superplasticizer. Concrete can handle a much larger dosage than cement paste, largely due to the role of aggregates in limiting segregation. As explained earlier, Goldman and Bentur (1989) used progressively more superplasticizer as the silica fume content of their concrete was increased. It appears that, although the workability of their concrete was enhanced, the pastes became too fluid at the high superplasticizer contents, resulting in a reduction in strength similar to that observed in this study. Considering the small size of their test specimens, a $25 \mathrm{~mm}$ cube, it is unlikely that Goldman and Bentur could have observed the effects of segregation. For the balance of the report, reference to SF materials is directed to those with the $15 \mathrm{oz} / \mathrm{cwt}$ superplasticizer dosage rate.

\section{Effects of Aggregate}

Fig. 7 illustrates the effects of aggregate on material strength for $w / c=0.33$ and 0.39 . For each $\mathrm{w} / \mathrm{c}$, the addition of sand to cement paste to obtain mortar and the addition of coarse aggregate to mortar to obtain concrete reduces the strength of the materials. The addition of aggregate reduces strength (1) because aggregate is stiffer than cement paste, even for the high strength cement pastes used in this study, and (2) because the interfaces between aggregate particles and cement paste serve as flaws from which cracks can propagate. Because aggregate is stiffer than cement paste, it causes stress concentrations in the paste which can initiate additional cracks. The greater the number and size of flaws and crack initiation sites, the lower will be the stress needed to cause failure.

Table 3 and Figs. 8 and 9 compare the ratios of mortar strength to paste strength, $\mathrm{f}_{\mathrm{m}}^{\prime} / \mathrm{f}_{\mathrm{p}}^{\prime}$, for each water-cement ratio, at 3,7, and 28 days. Table 3 and Fig. 10 compare ratios of concrete 
strength to paste strength, $\mathrm{f}^{\prime} / \mathrm{f}_{\mathrm{p}}^{\prime}$ at the same ages. In every case, the highest relative mortar and concrete strengths belong to the SP materials and the lowest relative strengths belong to the SF materials.

With this as the only evidence and following reasoning used by Goldman and Bentur (1989) and Rosenburg and Gaidis (1989), one might conclude that the lowest interfacial strengths between cement paste and aggregate existed in the mortar and concrete containing silica fume, while the highest interfacial strength was provided when superplasticizer was used as the only admixture. Of course, this line of reasoning is wrong, because the compressive strength of these materials is affected by more than the interfacial strength. The relative values of $f_{\mathrm{m}}^{\prime} / \mathrm{f}_{\mathrm{p}}^{\prime}$ are probably affected more by the impact of segregation on $f^{\prime} p$ than they are by any differences in interfacial strength.

Fig. 11 compares the relative strengths of the concretes to the corresponding mortars. The $f^{\prime} d f^{\prime} m$ ratios are nearly independent of admixture and $w / c$. This suggests that changes observed at the cement paste-coarse aggregate interface due to the use of silica fume (Regourd 1985, Bentur and Cohen 1987, Bentur, Goldman and Cohen 1988) have little effect on the compressive strength of concrete.

The argument can be made that comparisons of relative strengths should not be made based on w/c or age, but rather on paste (or mortar) strength. With this in mind, Fig. 12 compares the values of $f^{\prime} m / f_{p}^{\prime}$ and $f^{\prime} d f_{p}^{\prime}$ as a function of paste strength, while Fig. 13 compares the values of $f^{\prime} d f^{\prime} m$ as a function of mortar strength.

In Fig. 12, the values of $f^{\prime} m / f_{p}^{\prime}$ and $f^{\prime} d f^{\prime}{ }_{p}$ form a series of bands based on the type of cementitious material matrix, with the SF materials being uniformly lower than the NA materials, which are in turn lower than the SP materials. Overall, the higher the absolute strength of the paste, whether due to $\mathrm{w} / \mathrm{c}$, age, or admixture, the lower the relative strength of the mortar or concrete and the greater the apparent detrimental effect of the aggregate on the paste. If paste-aggregate bond strength is the dominant factor, the ratios of strength should increase with increasing paste 
strength because of the stronger interfacial region.

Fig. 13 shows that the values of $\mathrm{f}^{\prime} / \mathrm{f}^{\prime} \mathrm{m}$ form a tight band and are very much less sensitive to matrix strength than the values of $f^{\prime} \mathrm{m} / \mathrm{f}_{\mathrm{p}}^{\prime}$. There is a slight trend toward decreasing values of $f^{\prime} d / f_{m}^{\prime}$ with increasing mortar strength. However, at 28 days, the values of $f^{\prime} d f^{\prime} m$ increase for the NA and SF concretes with increasing mortar strength. The lower sensitivity of $f^{\prime} d f^{\prime} m$ to mortar, strength compared to the sensitivity of $f^{\prime} \mathrm{m}^{\prime} \mathrm{f}_{\mathrm{p}}^{\prime}$ to paste strength, suggests that coarse aggregate reduces mortar strength in generally the same way for all of the concretes.

Considering the observed negative effects of aggregate on the strength of cement paste, the concept of aggregate acting as a reinforcing filler (Goldman and Bentur 1989) appears to be without a basis, at least for specimens tested in uniaxial compression. The concept may be valid, however, for cubes due to the high triaxial compression obtained because of end restraint.

\section{A Final Observation}

One final observation concerns the report by Rosenberg and Gaidis (1990) that the addition of silica fume resulted in no increase in cement paste strength when silica fume was used to replace cement on an equal volume basis. Fig. 14 illustrates the test results for cement paste versus watercementitious material ratio with the $\mathrm{w} / \mathrm{c}$ based on the weight of an equivalent volume of portland cement; that is, when silica fume is used, the calculated cementitious material content (on a cement volume basis $)=\mathrm{W}_{\mathrm{c}}+\left(\mathrm{SG}_{\mathrm{c}} / \mathrm{SG}_{\mathrm{sf}}\right) \mathrm{W}_{\mathrm{sf}}$, where $\mathrm{W}=$ weight and $\mathrm{SG}=$ specific gravity. The result of this conversion is to shift SF pastes to lower equivalent w/c's. As shown in Fig. 14, the results indicate approximately equal strengths are obtained at 3 days for pastes with equal cement volume based w/c's. However, at later ages, the SF pastes show a distinctly higher strength. The reason Rosenberg and Gaidis (1990) obtained equal strengths for SF and NA pastes may be due to the very low $w / c, 0.24$, which resulted in very early self-desiccation, subsequently limiting the pozzolanic effect at later ages.

As this report draws to a close, we are faced with the question: Why does concrete con- 
taining silica fume as a partial replacement for cement have a higher strength than concrete without silica fume? We are faced with two facts: 1 . SF cement pastes are stronger than NA pastes, if the pastes are not excessively fluid. 2. NA, SP and SF materials exhibit similar values of $f^{\prime} d f^{\prime} m$. These observations lead to the conclusions that SF concrete has a higher strength primarily because of the higher strength of the paste and changes in the properties of the paste-aggregate interface due to the use of silica fume have little effect on the compressive strength of concrete.

\section{CONCLUSIONS}

The following conclusions are based on the results and analyses presented in this report.

1. The replacement of cement by silica fume and the addition of a superplasticizer increases the strength of cement paste.

2. Cement paste specimens can exhibit a reduced strength compared to other specimens of the same water-cementitious material ratio if the material segregates during fabrication. Segregation can be caused by high superplasticizer dosages that do not result in the segregation of concrete with the same water-cementitious material ratio.

3. Concrete containing silica fume as a partial replacement for cement exhibits an increased compressive strength because of the improved strength of its cement paste constituent.

4. Changes in the paste-aggregate interface caused by silica fume have little effect on the uniaxial compressive strength of concrete.

\section{ACKNOWLEDGEMENTS}

This report is based on research performed by Xiaofeng Cong in partial fulfillment of the requirements of the Master of Science in Civil Engineering degree at the University of Kansas. The cement for this study was supplied by the Ash Grove Cement Company. The silica fume was supplied by Elkem Materials, Inc., and the superplasticizer was supplied by Master Builders, Inc. 


\section{REFERENCES}

ASTM. (1986). "Standard Test Method for Compressive Strength of Cylindrical Concrete Specimens," (ASTM C 39-86), 1990 Annual Book for ASTM Standards, Vol. 4.02, pp. 20-24.

ASTM. (1990). "Standard Test Method for Compressive Strength of Hydraulic Cement Mortars (Using 2-in. or 50-mm Cube Specimens)," (ASTM C 109-90), 1990 Annual Book for ASTM Standards, Vol. 4.01, pp. 60-64.

ASTM. (1982). "Standard Practice for Mechanical Mixing of Hydraulic Cement Pastes and Mortars of Plastic Consistency," (ASTM C 305-82)(Reapproved 1987), 1990 Annual Book for ASTM Standards, Vol. 4.01, pp. 201-203.

Bentur, Arnon, and Cohen, Menashi D. (1987). "Effect of Condensed Silica Fume on the Microstructure of the Interfacial Zone in Portland Cement Mortars," Journal, American Ceramic Society, Vol. 70, No. 10, Oct., pp. 738-743.

Bentur, Arnon, Goldman, Ariel, and Cohen, Menashi D. (1988). "The Contribution of the Transition Zone to the Strength of High Quality Silica Fume Concretes," Bending in Cementitious Composites, S. Mindess and S. P. Shah, Editors, Material Research Society, Symposium Proceedings, Vol. 114, Boston, pp. 97-104.

Darwin, David, Shen, Zhenjia, and Harsh, Shraddhaker. (1988). "Silica Fume, Bond Strength, and the Compressive Strength of Mortar," Bending in Cementitious Composites, S. Mindess and S. P. Shah, Editors, Material Research Society, Symposium Proceedings, Vol. 114, Boston, pp. 105-110.

Darwin, David, and Slate, F. O. (1970). "Effect of Paste-Aggregate Bond Strength on Behavior Concrete," Journal of Materials, Vol. 5, No. 1, Mar., pp. 86-98.

Detwiler, Rachel J., and Mehta, P. Kumar. (1989). "Chemical and Physical Effects of Silica Fume on the Mechanical Behavior of Concrete," ACI Materials Journal, Vol. 86, No. 6, Nov.-Dec., pp. 609-614.

Feldman, R. F., and Huang, Cheng-Yi. (1985). "Properties of Portland Cement-Silica Fume Paste II. Mechanical Properties," Cement and Concrete Research, Vol. 15, No. 6, Nov., pp. 943-952.

Goldman, Ariel, and Bentur, Arnon. (1989). "Bond Effects in High-Strength Silica Fume Concretes," ACI Materials Journal, Vol. 86, No. 5, Sep.-Oct., pp. 440-447.

Huang, Cheng-Yi, and Feldman, R. F. (1985). "Influence of Silica Fume on the Microstructural Development in Cement Mortars," Cement and Concrete Research, Vol. 15, No. 2, Mar., pp. 285294.

Maher, Ataullah, and Darwin, David. (1977). "Microscopic Finite Element Model of Concrete," Proceedings, First International on Mathematical Modeling, (St. Louis, Aug.-Sep.-1977), University of Missouri-Rolla, Vol, II, pp. 1705-1714.

Mehta, P. K., and Gjorv, O. E. (1982). "Properties of Portland Cement Concrete Containing Fly Ash and Condensed Silica-Fume," Cement and Concrete Research, Vol. 12, No. 5, Sep., pp. 587- 
595.

Nepper-Christensen, Palle, and Nielson, Tommy P. H. (1969). "Modal Determination of the Effect of Bond Between Coarse Aggregate and Mortar on the Compressive Strength of Concrete," ACI Journal, Proceedings, Vol. 66, No. 1, Jan., pp. 69-72.

Perry, C., and Gilliot, J. E. (1977). "The Influence of Mortar-Aggregate Bond Strength on the Behavior of Concrete in Uniaxial Compression," Cement and Concrete Research, Vol. 7, No. 5, Sep., pp. 553-564.

Regourd, M. (1985). "Microstructure of High Strength Cement Based Materials," Very High Strength Cement-Based Materials, J. F. Young, Editor, Materials Research Society, Symposium Proceedings, Vol. 42, Boston, pp. 3-17.

Rosenberg, Arnold M., and Gaidis, James M. (1989). "A New Mineral Admixture for HighStrength Concrete," Concrete International, Vol. 11, No. 4, Apr., pp. 31-36.

Rosenberg, Arnold M., and Gaidis, James M. (1990). "Letters--Authors' Response," Concrete International, Vol. 12, No. 3, Mar., pp. 8-9.

Shah, Surendra P., and Chandra, Sushil. (1968). "Critical Stress, Volume Change, and Microcracking of Concrete," ACI Journal, Proceedings, Vol. 65, No. 9, Sep., pp. 770-781. 
TABLE 1 - MIXTURE PROPORTIONS ( $\mathrm{lb} /$ cubic yard )*

\begin{tabular}{|c|c|c|c|c|c|c|c|c|c|c|c|}
\hline & $\begin{array}{l}\text { NOMINAL } \\
W / C^{* *}\end{array}$ & $\begin{array}{l}\text { ACTUAL } \\
W / C^{* *}\end{array}$ & WATER & CEMENT & $\begin{array}{l}\text { SILICA } \\
\text { FUME } \\
\end{array}$ & SAND & $\begin{array}{l}\text { COARSE } \\
\text { AGG. }\end{array}$ & $S P(f 1.0 z)$ & $\begin{array}{c}\text { SP } \\
\text { SOLIDS WT } \\
\end{array}$ & $\begin{array}{c}\text { SLUMP } \\
\text { (in.) } \\
\end{array}$ & TEMP. $(F)$ \\
\hline \multirow[t]{4}{*}{ NA pasto } & 0.30 & 0.30 & 804 & 2671 & & & & & & & 76 \\
\hline & 0.33 & 0.33 & 842 & 2548 & & & & & & & 72 \\
\hline & 0.36 & 0.36 & 878 & 2436 & & & & & & & 76 \\
\hline & 0.39 & 0.39 & 910 & 2333 & & & & & & & 74 \\
\hline \multirow[t]{4}{*}{ SP paste } & 0.30 & 0.298 & 797 & 2671 & & & & $409(15)^{* * \pi *}$ & 12.84 & & 72 \\
\hline & 0.33 & 0.328 & 835 & 2548 & & & & $390(15)$ & 12.25 & & 72 \\
\hline & 0.36 & 0.358 & 871 & 2436 & & & & $373(15)$ & 11.71 & & 73 \\
\hline & 0.39 & 0.387 & 904 & 2333 & & & & $359(15)$ & $\$ 1.27$ & & 74 \\
\hline \multirow[t]{5}{*}{ SF paste } & 0.33 & 0.326 & 807 & 2101 & 372 & & & $379(15)$ & 11.90 & & 76 \\
\hline & 0.33 & 0.325 & 803 & 2101 & 372 & & & $631(25)$ & 11.37 & & 76 \\
\hline & 0.33 & 0.33 & 817 & 2101 & 372 & & & $890(30)$ & 10.90 & & 76 \\
\hline & 0.36 & 0.357 & 844 & 2011 & 372 & & & $362(15)$ & 19.82 & & 76 \\
\hline & 0.39 & 0.387 & 879 & 1929 & 372 & & & 347 (15) & 27.60 & & 76 \\
\hline \multirow[t]{4}{*}{ NA mortar } & 0.30 & 0.30 & 430 & 1433 & & 1963 & & & & & 73 \\
\hline & 0.33 & 0.33 & 451 & 1367 & & 1963 & & & & & 73 \\
\hline & 0.36 & 0.36 & 470 & 1307 & & 1963 & & & & & 74 \\
\hline & 0.39 & 0.39 & 488 & 1253 & & 1963 & & & & & 74 \\
\hline \multirow[t]{4}{*}{ SP mortar } & 0.30 & 0.297 & 426 & 1433 & & 1963 & & $215(15)$ & 6.75 & & 73 \\
\hline & 0.33 & 0.327 & 447 & 1367 & & 1963 & & $206(15)$ & 6.47 & & 73 \\
\hline & 0.36 & 0.357 & 466 & 1307 & & 1963 & & $196(15)$ & 6.16 & & 76 \\
\hline & 0.39 & 0.387 & 485 & 1253 & & 1963 & & $188(15)$ & 5.90 & & 76 \\
\hline \multirow[t]{3}{*}{ SF mortar } & 0.33 & 0.327 & 433 & 1125 & 200 & 1963 & & $199(15)$ & 6.25 & & 72 \\
\hline & 0.36 & 0.357 & 453 & 1076 & 191 & 1963 & & $190(15)$ & 5.97 & & 72 \\
\hline & 0.39 & 0.387 & 471 & 1033 & 183 & 1963 & & $182(15)$ & 5.72 & & 72 \\
\hline \multirow{2}{*}{ NA conc. } & 0.33 & 0.33 & 305 & 924 & & 1326 & 1390 & & & $1 / 4$ & 74 \\
\hline & 0.39 & 0.39 & 329 & 844 & & 1326 & 1390 & & & $1 / 2$ & 74 \\
\hline \multirow[t]{2}{*}{ SP conc. } & 0.33 & 0.327 & 302 & 924 & & 1326 & 1390 & $139(15)$ & 4.36 & 1 & 74 \\
\hline & 0.39 & 0.387 & 327 & 844 & & 1326 & 1390 & $127(15)$ & 3.99 & $71 / 2$ & 74 \\
\hline \multirow[t]{4}{*}{ SF conc. } & 0.33 & 0.328 & 293 & 759 & 135 & 1326 & 1390 & $134(15)$ & 4.21 & 0 & 74 \\
\hline & 0.33 & 0.326 & 291 & 759 & 135 & 1326 & 1390 & $223(25)$ & 7.00 & $1 / 4$ & 76 \\
\hline & 0.33 & 0.33 & 295 & 759 & 135 & 1326 & 1390 & $268(30)$ & 8.42 & $51 / 2$ & 76 \\
\hline & 0.39 & 0.387 & 318 & 696 & 124 & 1326 & 1390 & $123(15)$ & 3.86 & $1 / 4$ & 72 \\
\hline
\end{tabular}

- -2 percent air assumed in concrete

$\mathrm{C}^{*}$ * ... cement plus silica fume

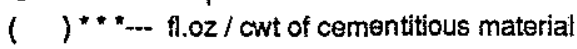


TABLE 2 -- STRENGTH OF SPECIMENS ( pSi)

\begin{tabular}{|c|c|c|c|c|}
\hline MATERIAL & $\begin{array}{l}\text { NOMINAL } \\
W / C^{*}\end{array}$ & $\begin{array}{c}\text { AGE } \\
3 \text { DAYS }\end{array}$ & $\begin{array}{c}\text { AGE } \\
7 \text { DAYS }\end{array}$ & $\begin{array}{c}\text { AGE } \\
28 \text { DAYS }\end{array}$ \\
\hline \multirow[t]{4}{*}{ NA paste } & 0.30 & 9850 & 12300 & 14410 \\
\hline & 0.33 & 8130 & 10810 & 12560 \\
\hline & 0.36 & 7110 & 9250 & 11920 \\
\hline & 0.39 & 5730 & 7400 & 10320 \\
\hline \multirow[t]{4}{*}{ SP paste } & $0.30(15)^{-.}$ & 9490 & 10920 & 13180 \\
\hline & $0.33(15)$ & 7510 & 8620 & 11640 \\
\hline & $0.36(15)$ & 6270 & 7350 & 10730 \\
\hline & $0.39(15)$ & 5690 & 6750 & 9330 \\
\hline \multirow[t]{5}{*}{ SF paste } & $0.33(15)$ & 8440 & 12130 & 16020 \\
\hline & $0.33(25)$ & 7570 & 10940 & 12380 \\
\hline & $0.33(30)$ & 6450 & 9480 & 11150 \\
\hline & $0.36(15)$ & 7870 & 10950 & 15140 \\
\hline & $0.39(15)$ & 6200 & 9330 & 13150 \\
\hline \multirow[t]{4}{*}{ NA mortar } & 0.30 & 8830 & 10600 & 12050 \\
\hline & 0.33 & 7500 & 9250 & 10880 \\
\hline & 0.36 & 6350 & 7690 & 10440 \\
\hline & 0.39 & 5650 & 6620 & 9620 \\
\hline \multirow[t]{4}{*}{ SP mortar } & $0.30(15)$ & 9070 & 10970 & 12490 \\
\hline & $0.33(15)$ & 7630 & 9530 & 11090 \\
\hline & $0.36(15)$ & 6860 & 8360 & 10600 \\
\hline & $0.39(15)$ & 6090 & 7030 & 9530 \\
\hline \multirow[t]{3}{*}{ SF mortar } & $0.33(15)$ & 6940 & 10330 & 12130 \\
\hline & $0.36(15)$ & 6000 & 8930 & 11720 \\
\hline & $0.39(15)$ & 4970 & 7830 & 11710 \\
\hline \multirow[t]{2}{*}{ NA conc. } & 0.33 & 5040 & 6300 & 7500 \\
\hline & 0.39 & 4150 & 4850 & 6320 \\
\hline \multirow[t]{2}{*}{ SP conc. } & $0.33(15)$ & 5330 & 6330 & 7380 \\
\hline & $0.36(15)$ & 4360 & 5010 & 6340 \\
\hline \multirow[t]{4}{*}{ SF conc. } & $0.33(15)$ & 4960 & 6360 & 8080 \\
\hline & $0.33(25)$ & 5510 & 7170 & 8990 \\
\hline & $0.33(30)$ & 3770 & 6470 & 8170 \\
\hline & $0.39(15)$ & 3670 & 4920 & 6830 \\
\hline
\end{tabular}

C * - coment pius silica fume

( )** - fl.oz / cwt of cemetitious material 
TABLE 3 -- RATIOS OF MORTAR AND CONCRETE STRENGTH TO PASTE STRENGTH AND RATIOS OF CONCRETE STRENGTH TO MORTAR STRENGTH

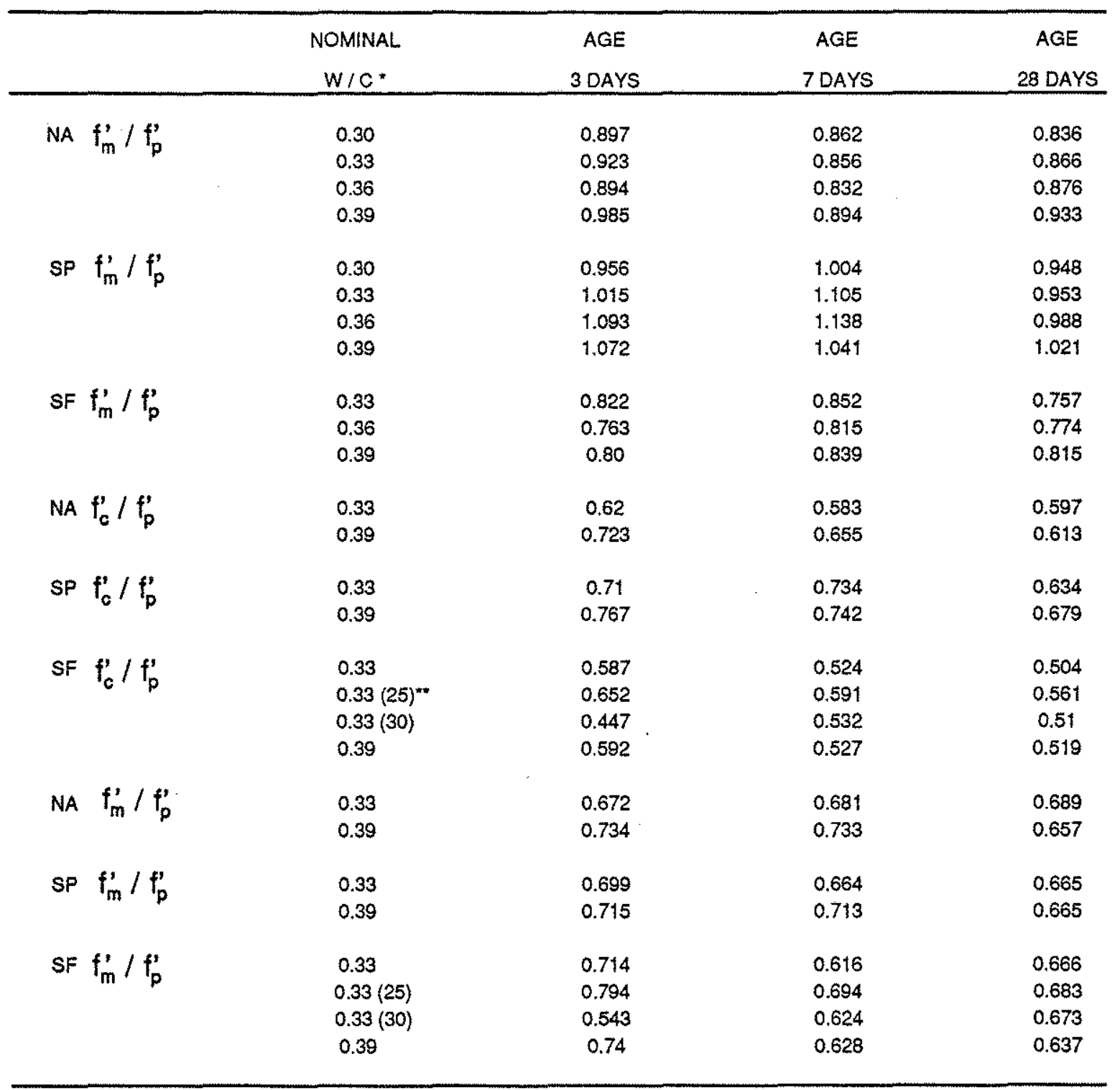

$C^{*}$-.. cament plus silica fume

( )**..- fl.oz / owt of cementitious material 


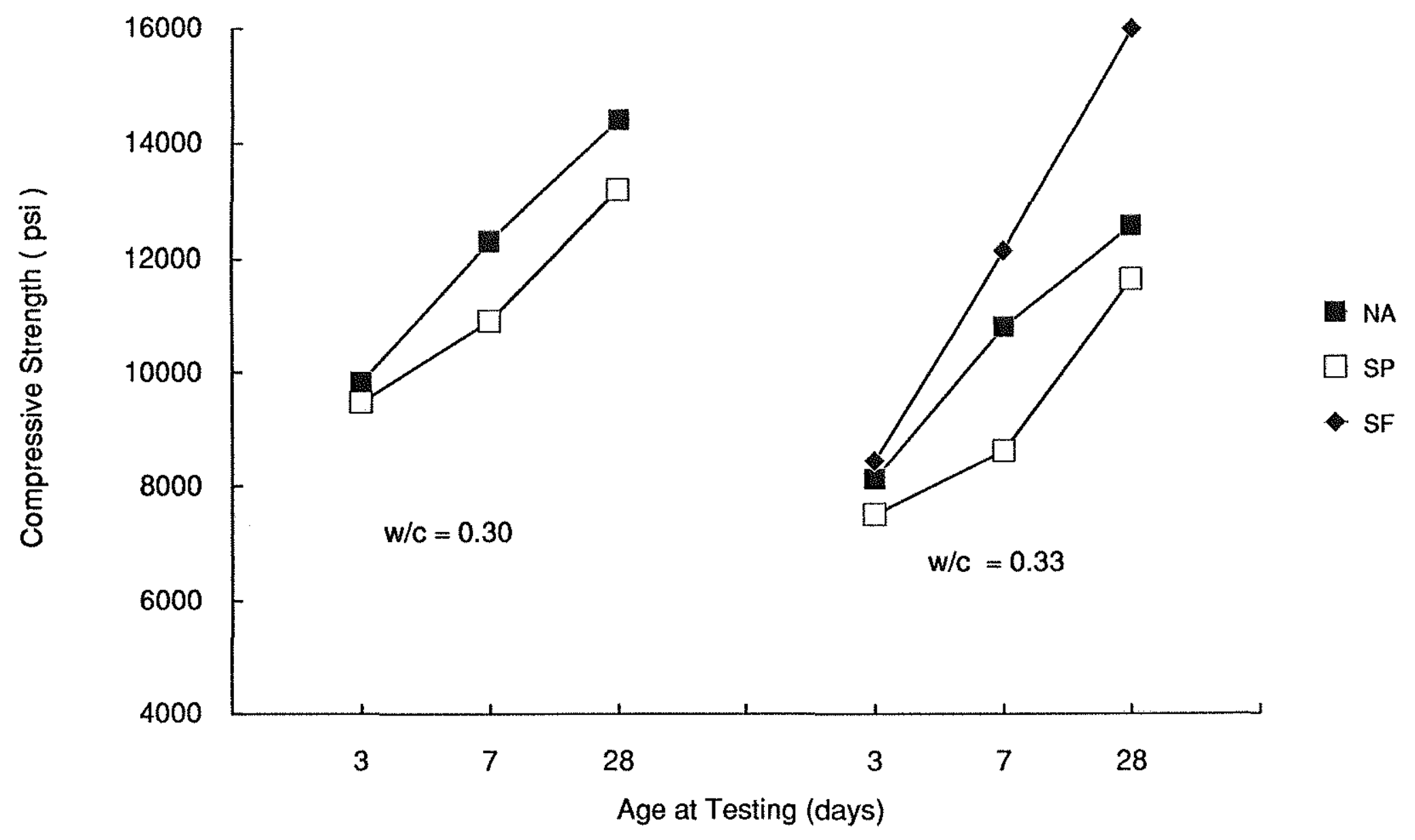

Fig. 1 -... Paste strength as a function of age for water-cementitious material ratios of 0.30 and 0.33 


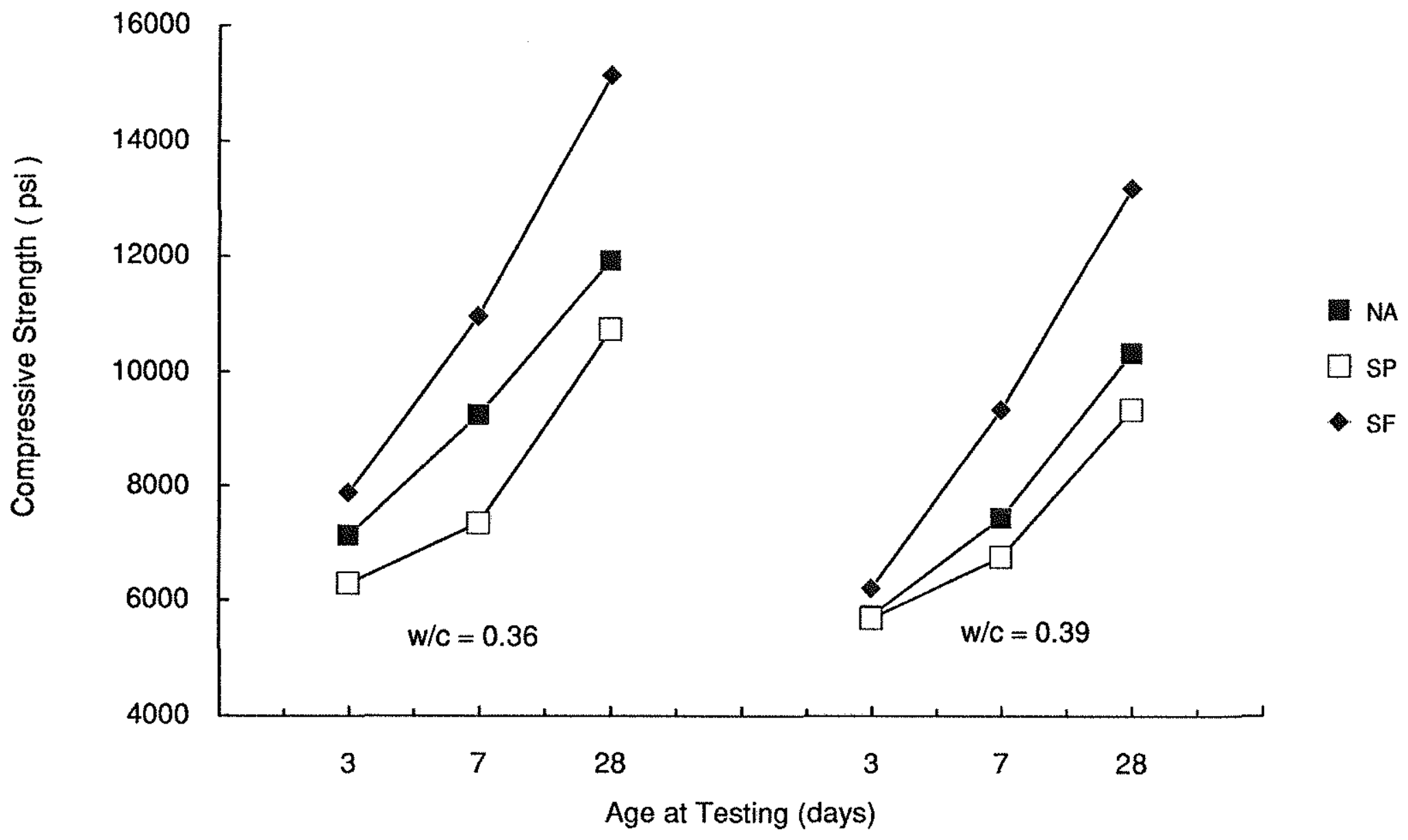

Fig.2 -.- Paste strength as a function of age for water-cementitious material ratios of 0.36 and 0.39 


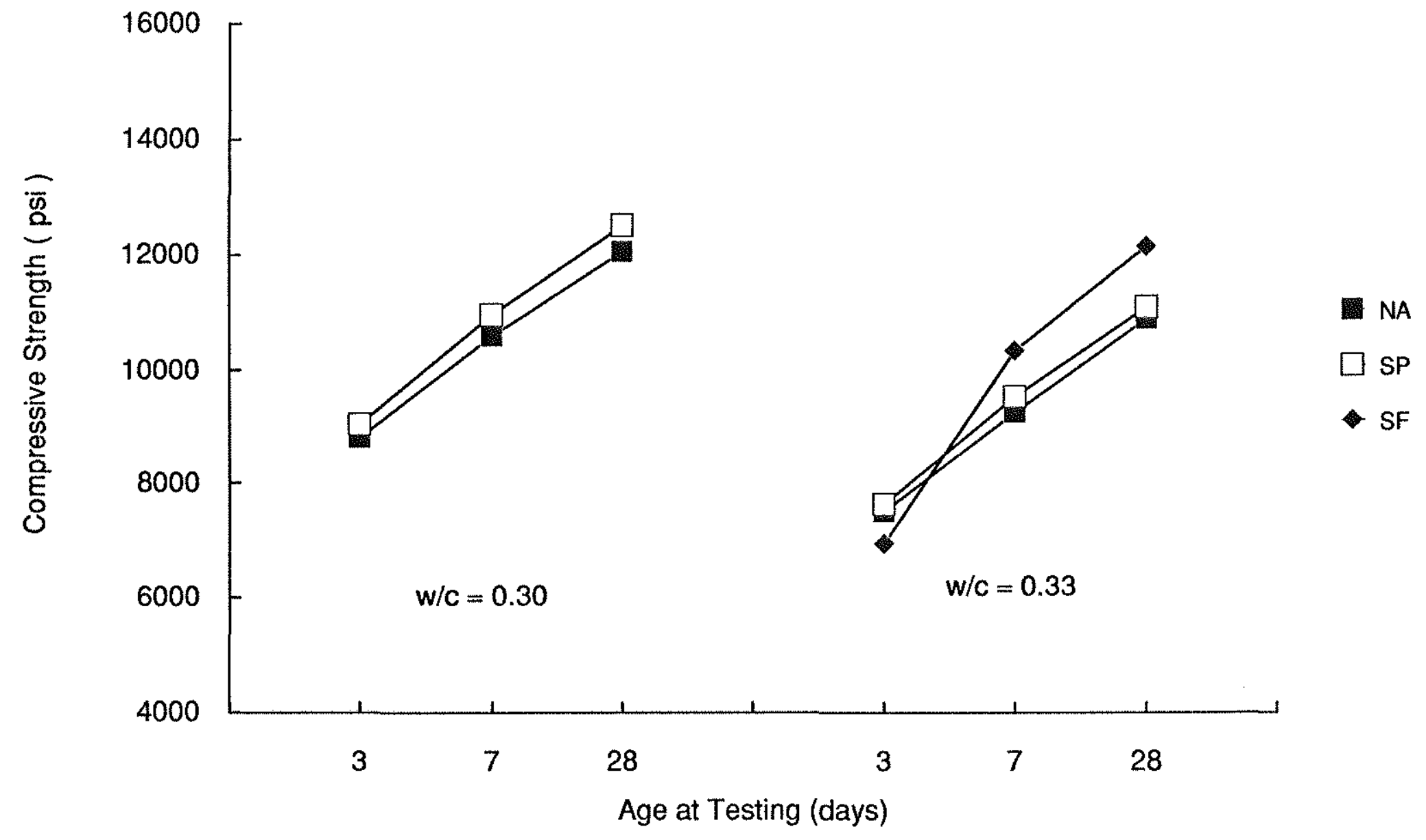

N

Fig.3 --- Mortar strength as a fuction of age for water-cementitious material ratios of 0.30 and 0.33 


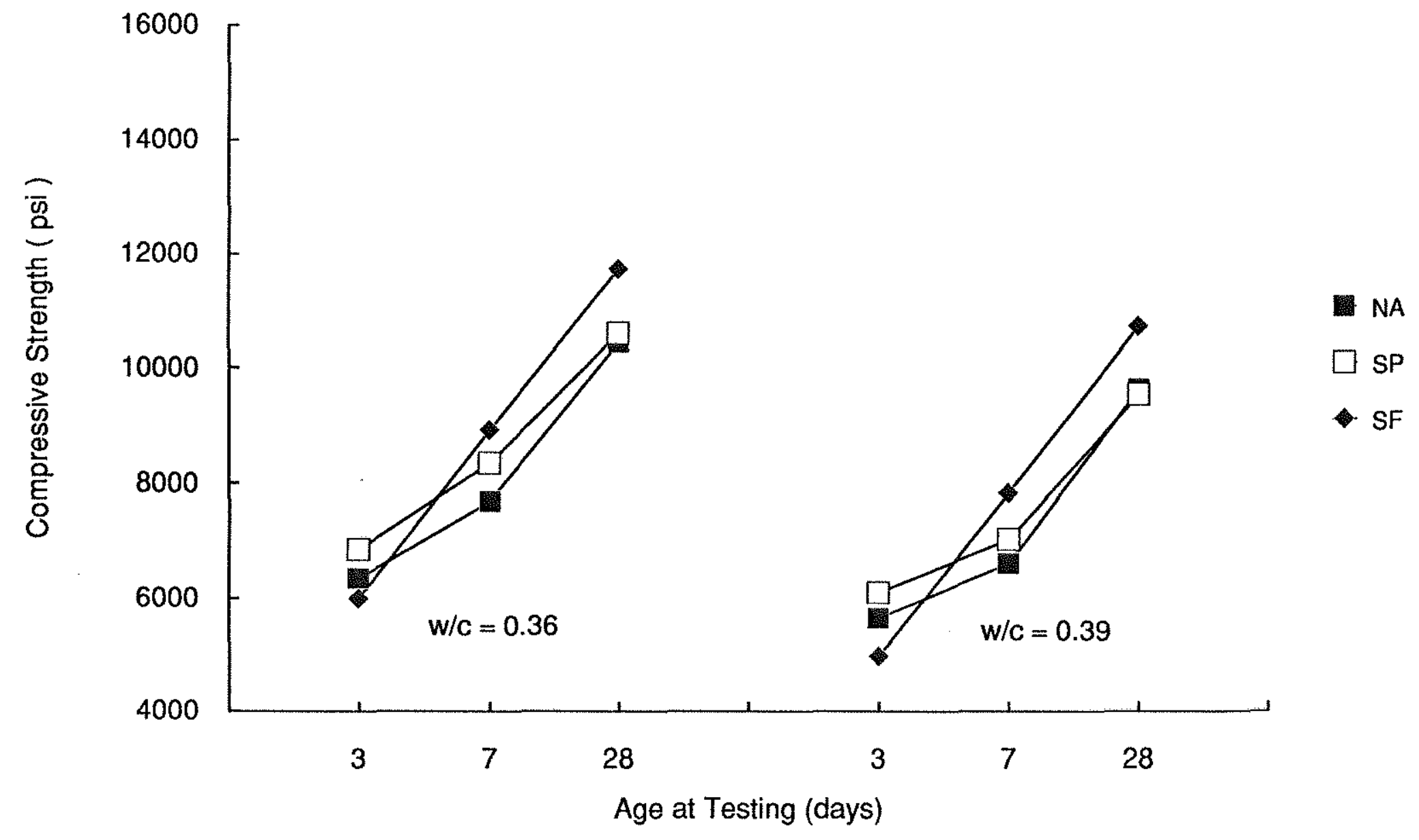

Fig.4 --- Mortar strength as a function of age for water-cementitious material ratios of 0.36 and 0.39 


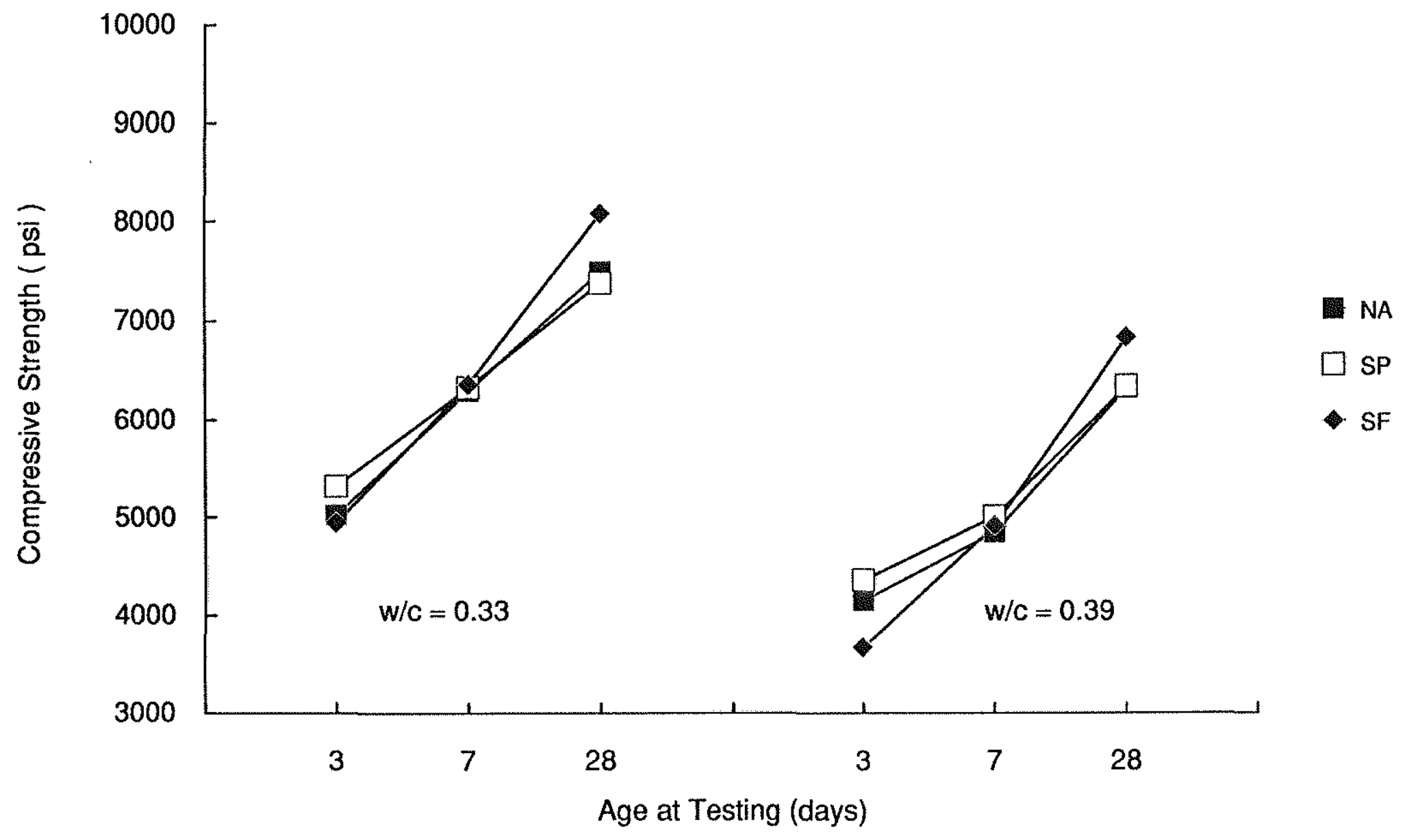

Fig.5 --. Concrete strength as a function of age for water-cementitious material ratios of 0.33 and 0.39 


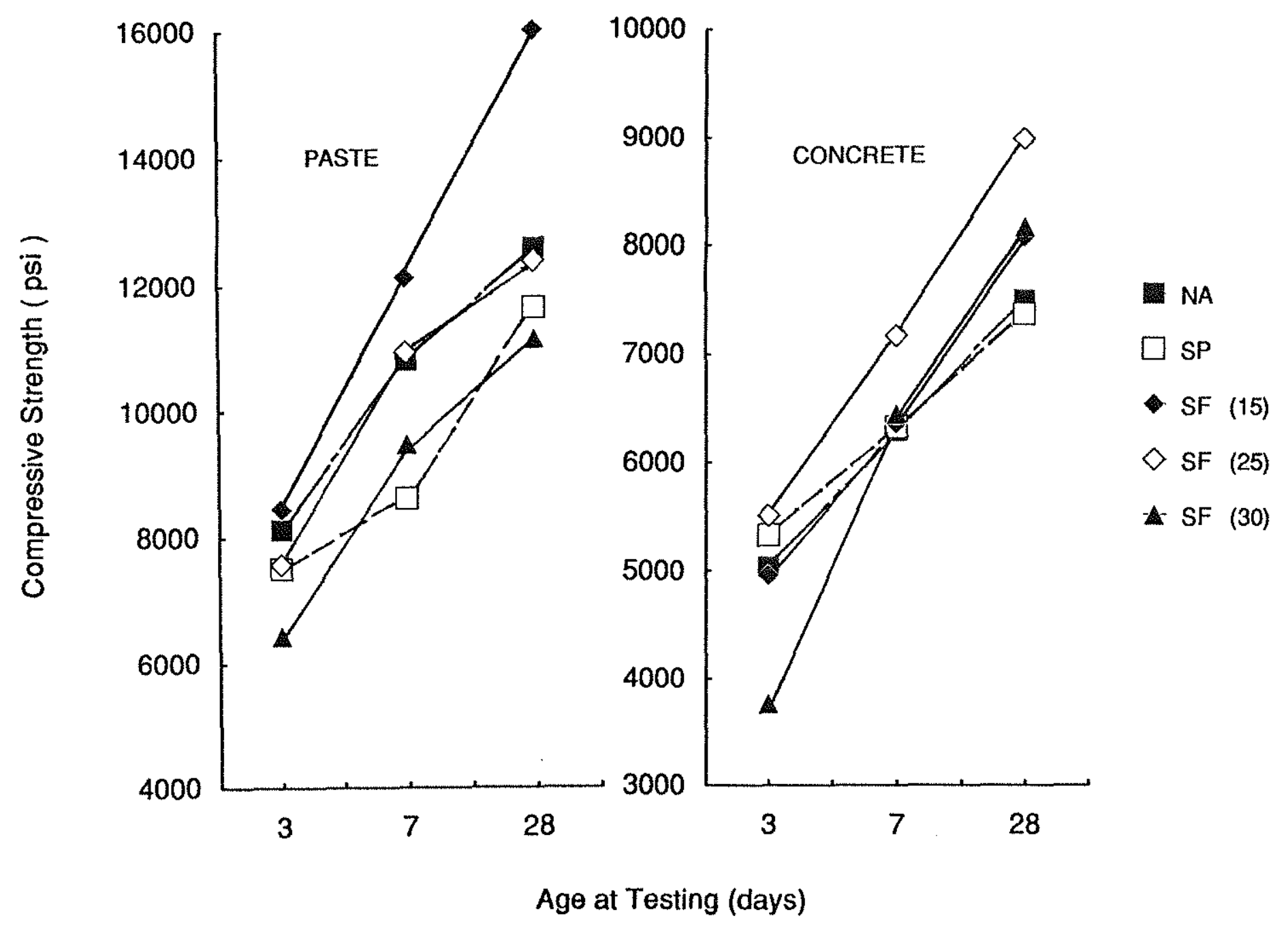

Fig.6 --- Paste and concrete strengths as a function of age for water-cementitious material ratio of 0.33 


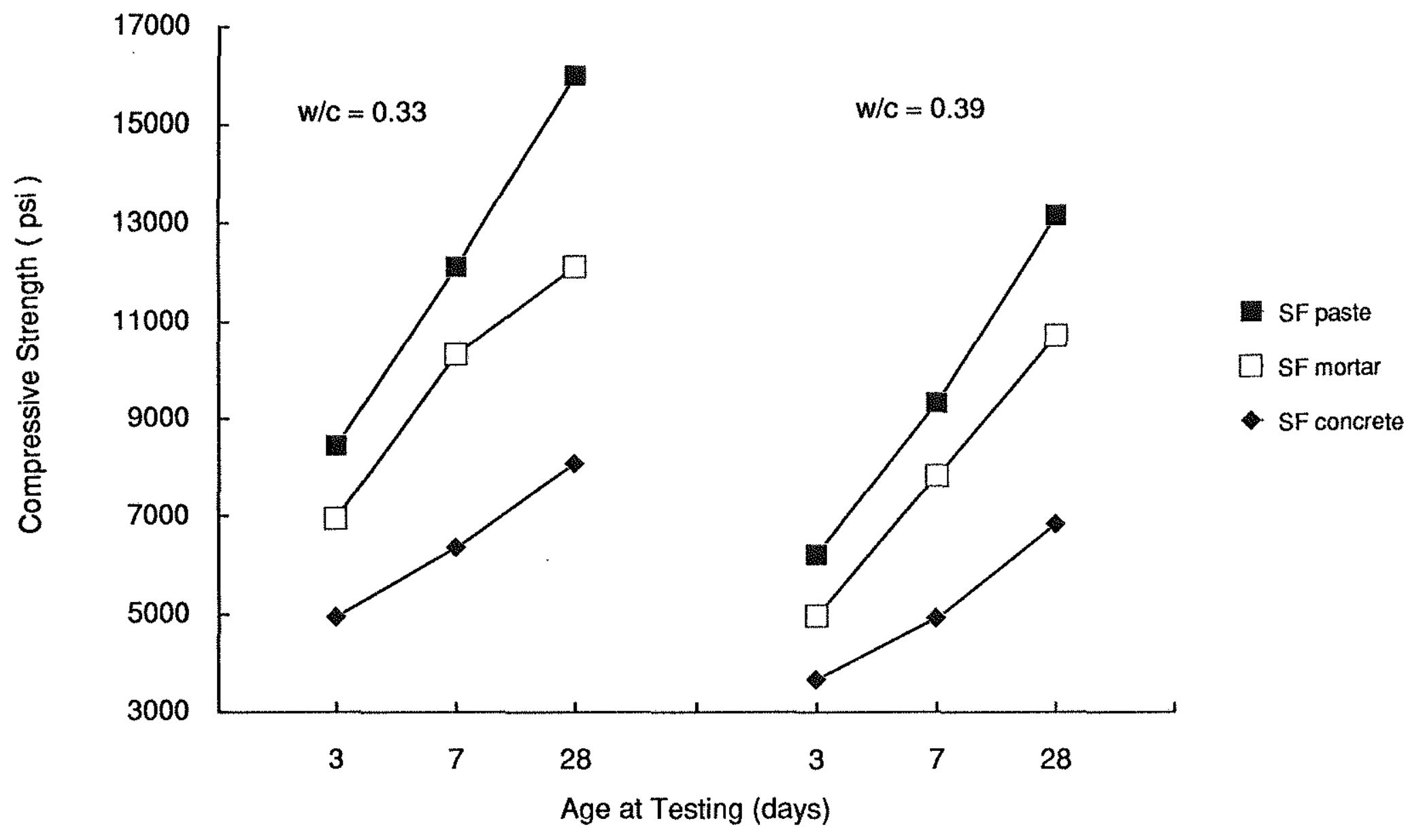

Fig.7 --- Strengths of SF paste, mortar and concrete as a function of age for water-cementitious material ratios of 0.33 and 0.39 


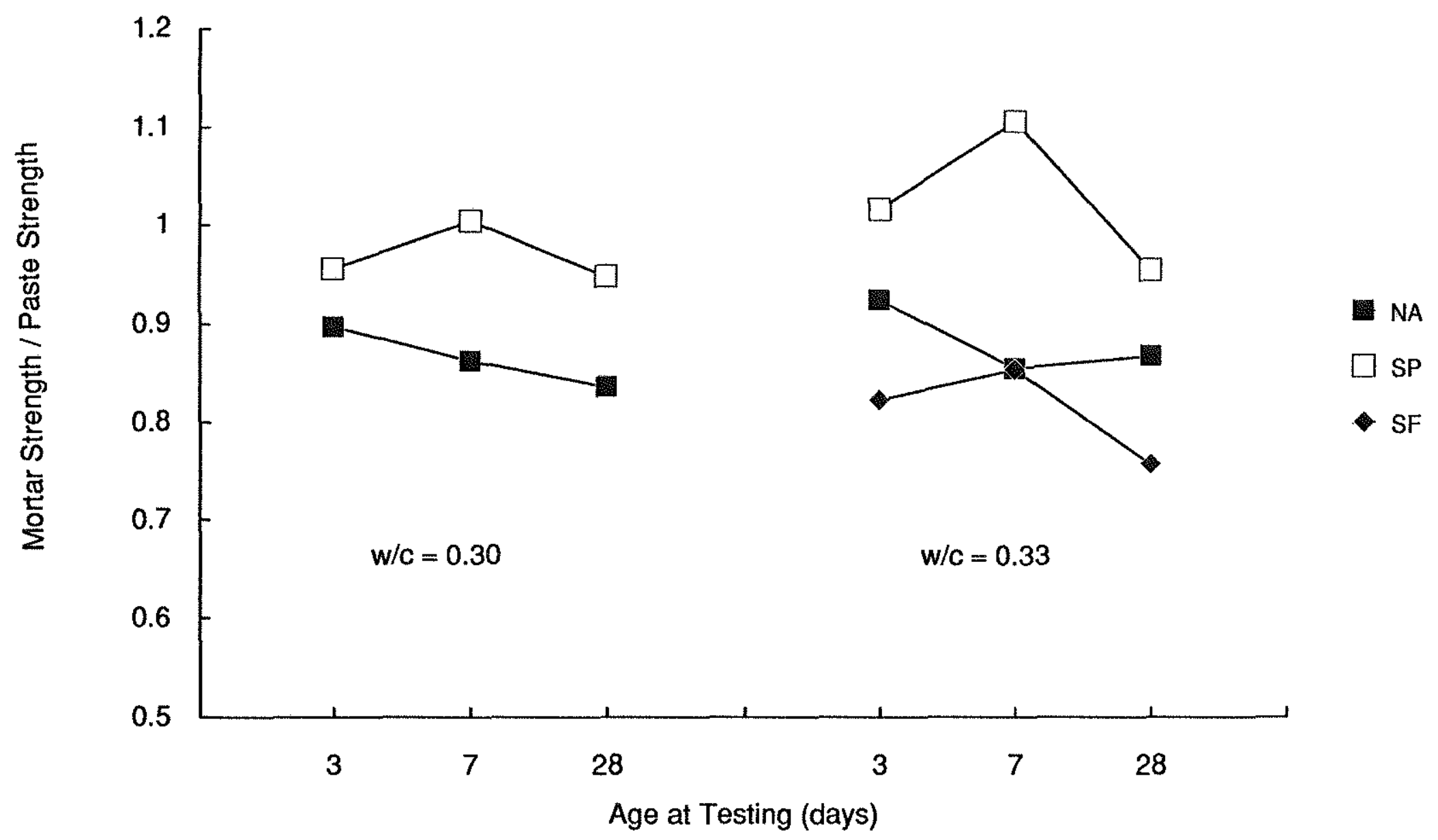

Fig.8 -- Ratios of mortar to paste strength as a function of age for water--cementitious material ratios of 0.30 and 0.33 


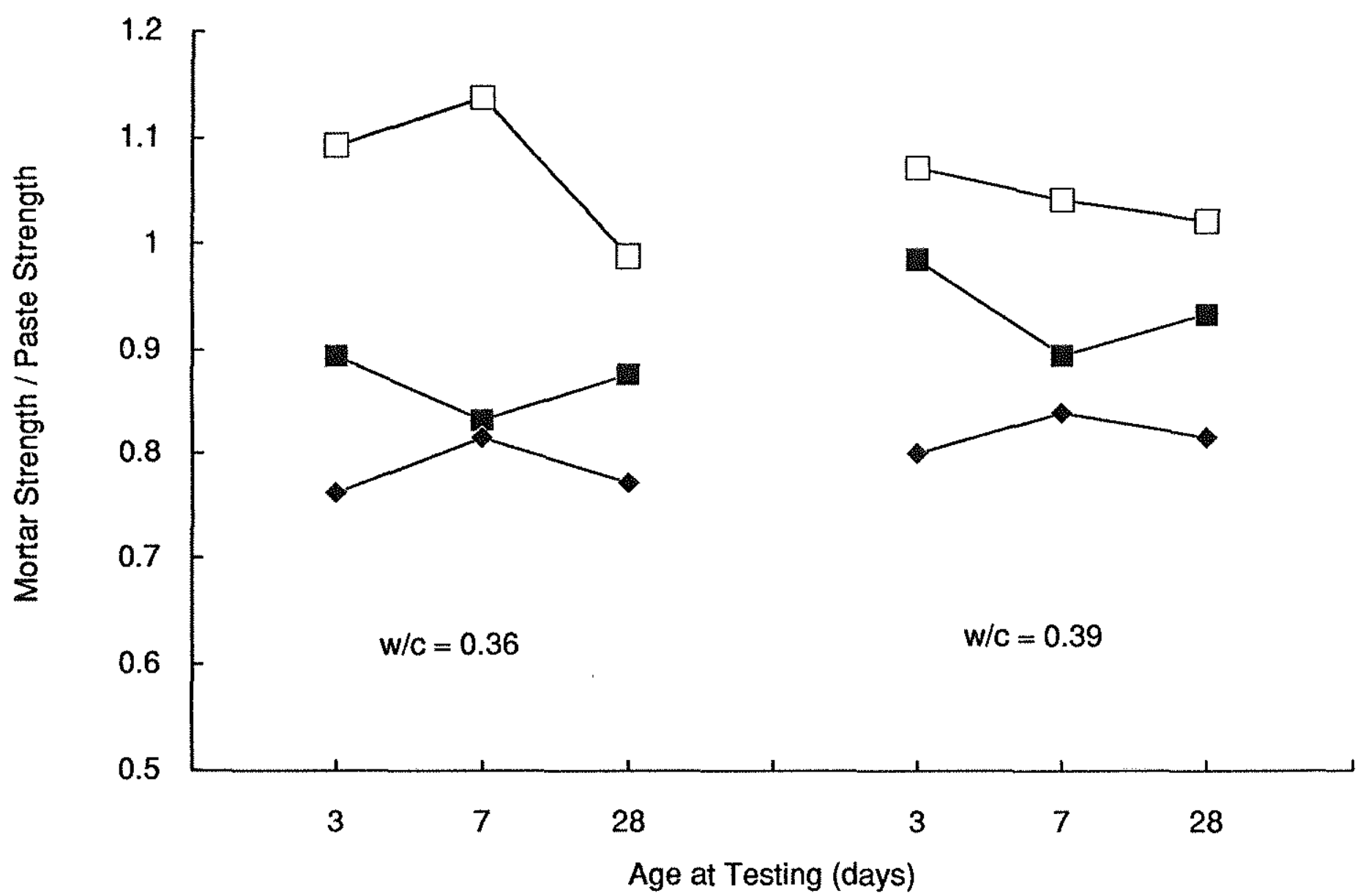

NA
$\square \mathrm{SP}$
$-\mathrm{SF}$

Fig.9 --- Ratios of mortar to paste strength as a function of age for water-cementitious material ratios of 0.36 and 0.39 


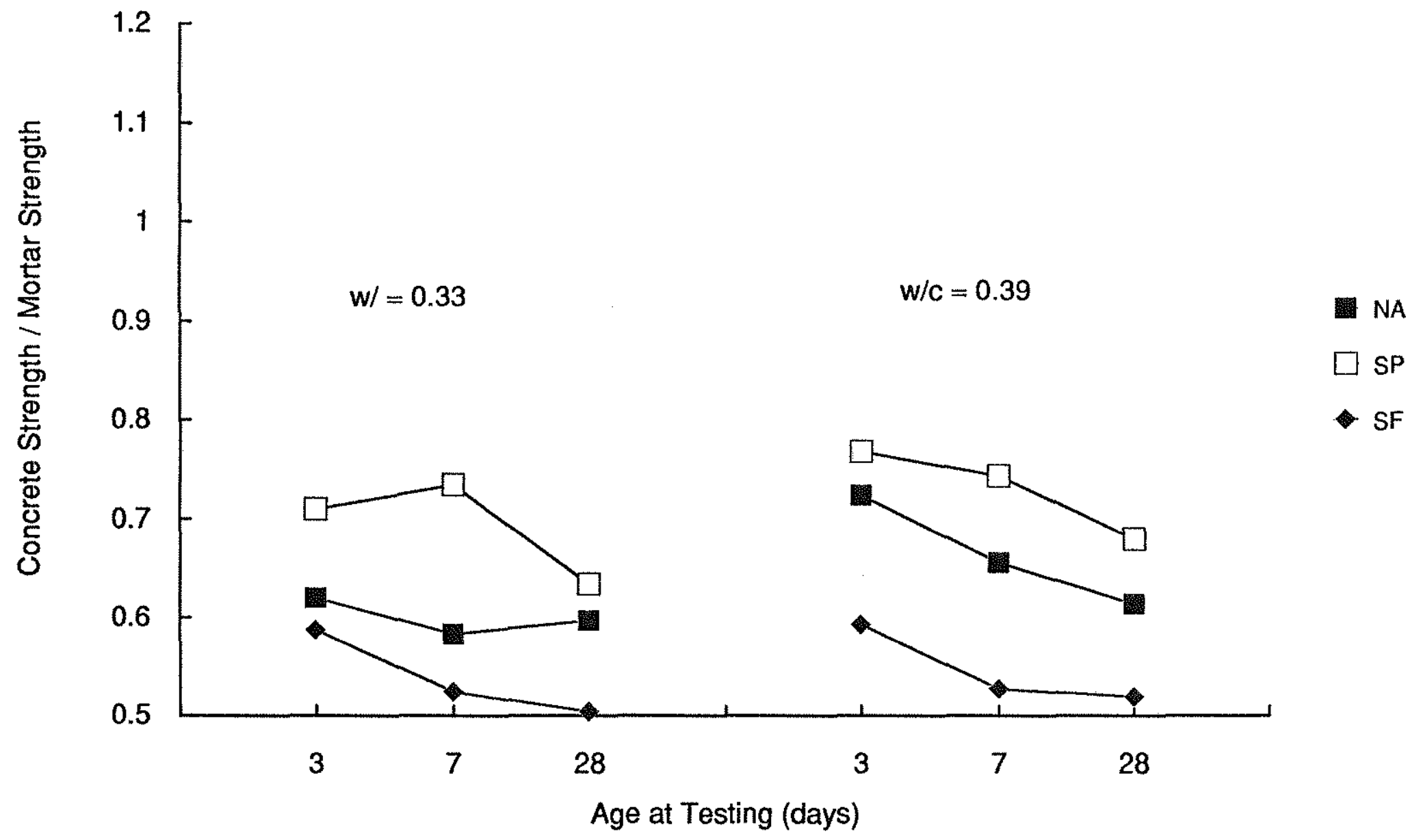

Fig.10 --- Ratios of concrete to paste strength as a function of age for water-cementitious material ratios of 0.33 and 0.39 


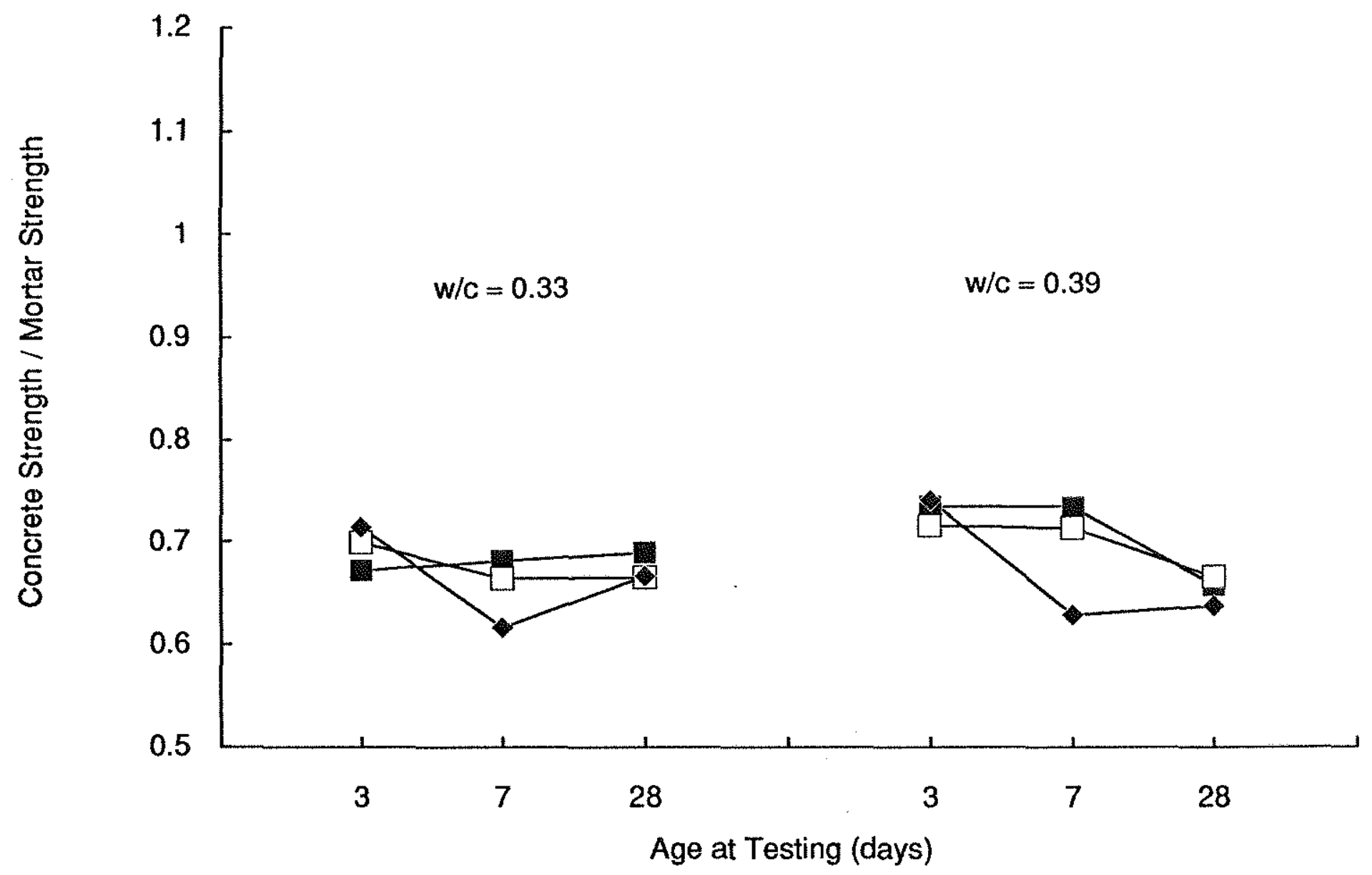

NA

$\square \mathrm{SP}$

- SF

Fig.11 --- Ratios of concrete to mortar strength as a function of age for water-cementitious material ratios of 0.33 and 0.39 


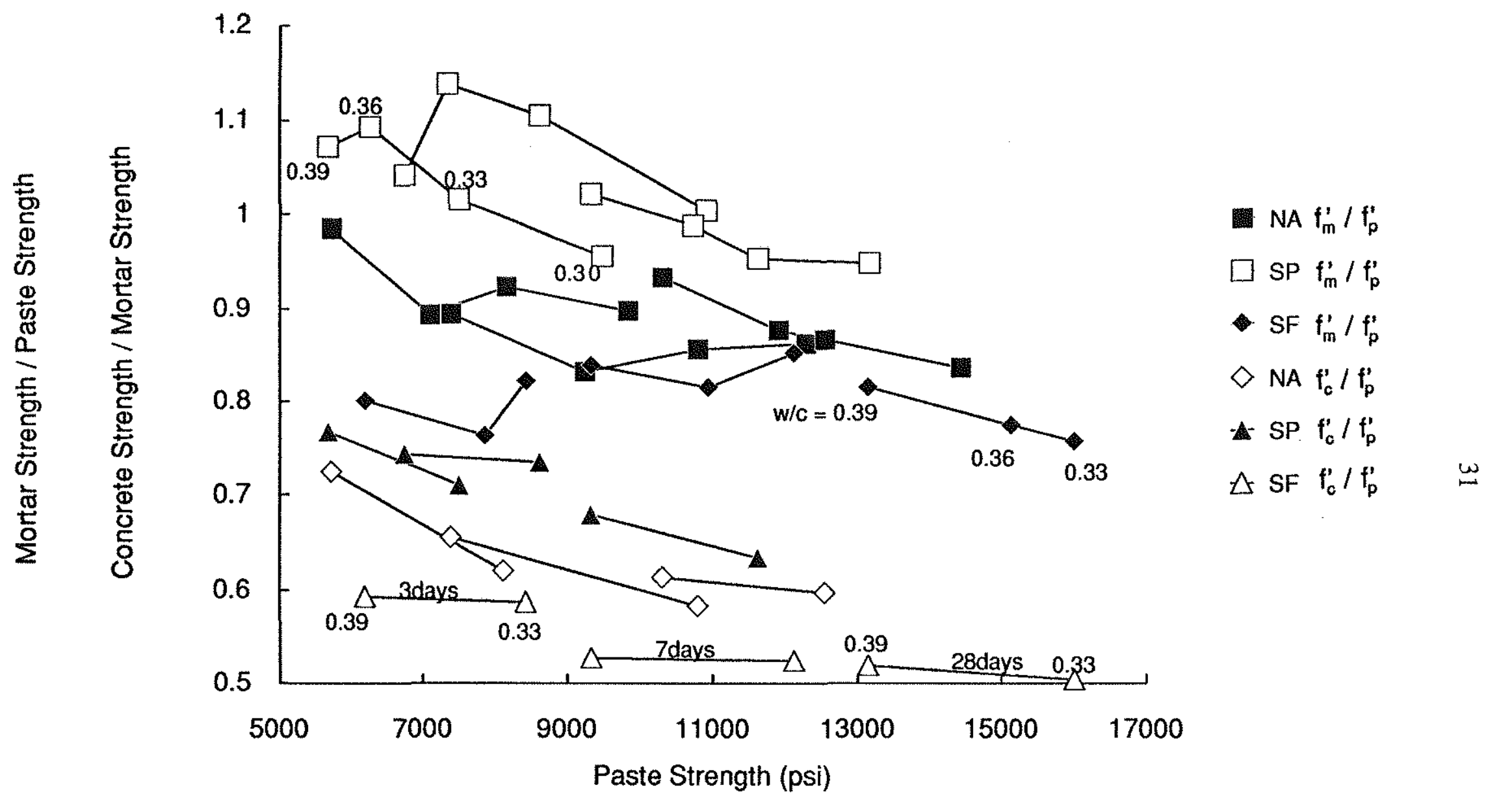

Fig.12 --- Ratios of concrete and mortar strengths to paste strength as a function of paste strength 


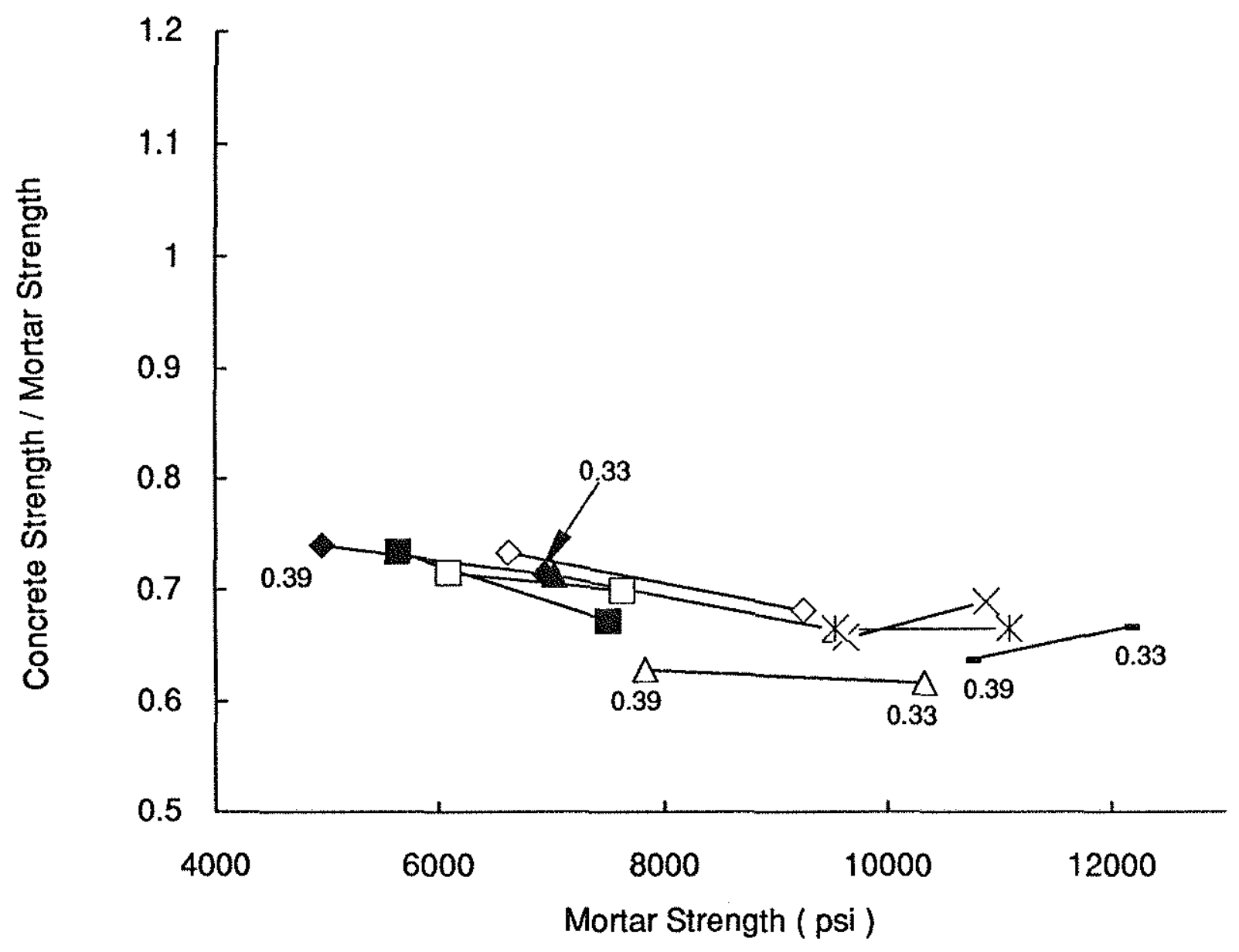

NA $f_{c}^{\prime} / f_{m}^{\prime}$ (3days)

$\square$ SP $f_{c}^{\prime} / f_{m}^{\prime}$ (3days)

- SF $f_{c}^{\prime} / f_{m}^{\prime}$ (3days)

$\diamond N A f_{c}^{\prime} / f_{m}^{\prime}$ (7days)

AS $f_{c}^{\prime} / f_{m}^{\prime}$ (7days)

$\triangle \mathrm{SF} \mathrm{f}_{\mathrm{c}}^{\prime} / \mathrm{f}_{\mathrm{m}}^{\prime}$ (7days)

$\times N A f_{c}^{\prime} / f_{m}^{\prime}$ (28days)

Ж SP $f_{c}^{\prime} / f_{m}^{\prime}$ (28days)

- $S F f_{c}^{\prime} / f_{m}^{\prime}$ (28days)

Fig.13 --- Ratios of concrete strength to mortar strength as a function of mortar strength for different water-cementitious material ratios and mortar strength 


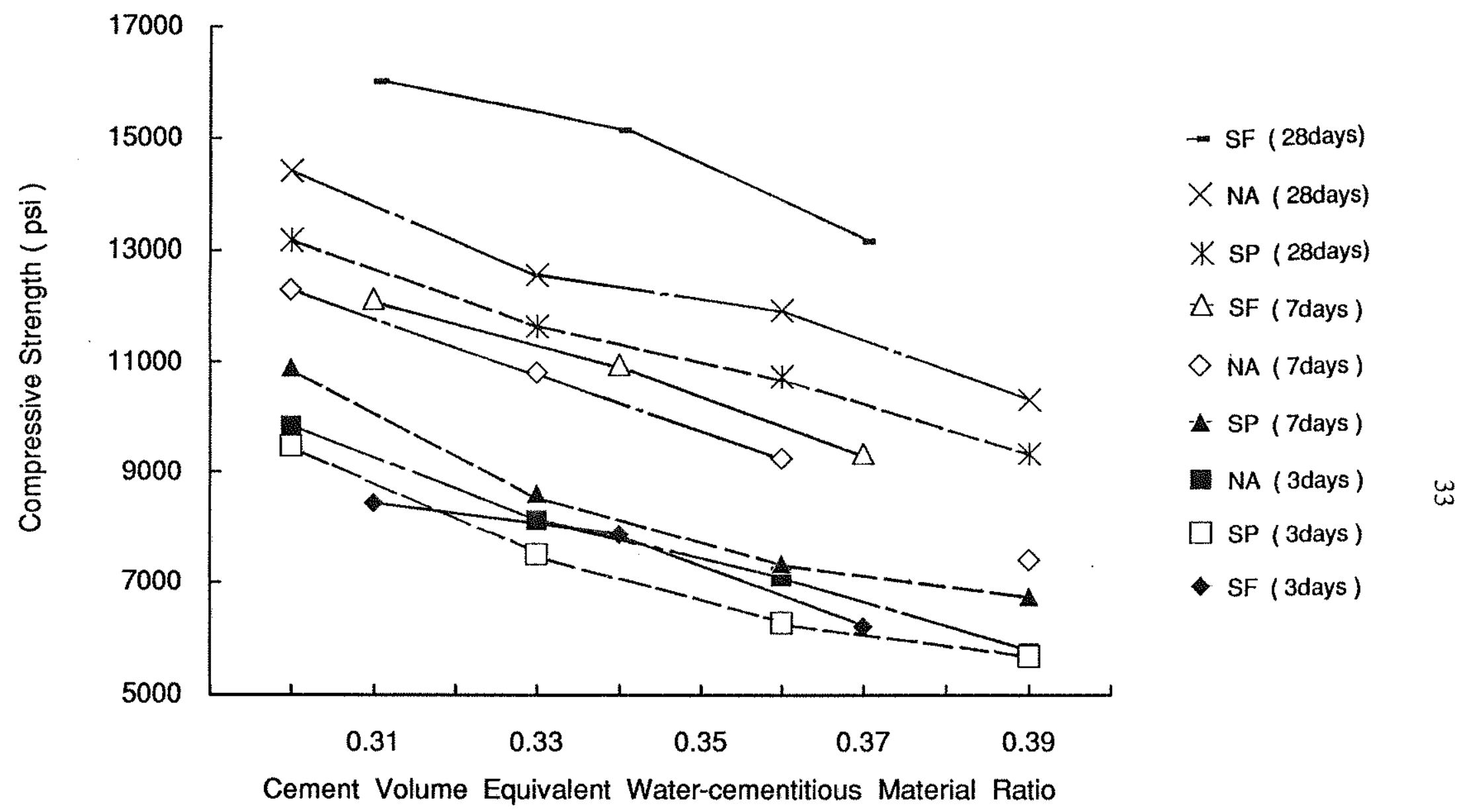

Fig.14 --- Paste strength as a function of cement volume equivalent water--cementitious material ratio 
APPENDIX A -- STRENGTH OF SPECIMENS (PSI)

\begin{tabular}{|c|c|c|c|c|c|c|c|}
\hline MATERIAL & $w / c^{*}$ & 3 DAYS & AVERAGE & 7 DAYS & AVERAGE & 28 DAYS & AVERAGE \\
\hline \multirow[t]{8}{*}{ NA paste } & 0.30 & 9829 & 9850 & 12269 & 12300 & 14585 & 14410 \\
\hline & & 9860 & & 12334 & & 14234 & \\
\hline & 0.33 & 8184 & 8130 & 11178 & 10810 & 12588 & 12560 \\
\hline & & 8069 & & 10431 & & 12525 & \\
\hline & 0.36 & 7121 & 7110 & 9301 & 9250 & 12203 & 11920 \\
\hline & & 7099 & & 9193 & & 11630 & \\
\hline & 0.39 & 5613 & 5730 & 7262 & 7400 & 10208 & 10320 \\
\hline & & 5852 & & 7544 & & 10423 & \\
\hline \multirow[t]{8}{*}{ SP paste } & 0.3 & 9646 & 9490 & 11228 & 12920 & 13563 & 13180 \\
\hline & & 9325 & & 10606 & & 12790 & \\
\hline & 0.33 & 7270 & 7510 & 8527 & 8620 & 11585 & 11640 \\
\hline & & 7753 & & 8717 & & 11684 & \\
\hline & 0.36 & 6093 & 6270 & 7315 & 7350 & 10566 & 10730 \\
\hline & & 6452 & & 7374 & & 10893 & \\
\hline & 0.39 & 5736 & 5690 & 6633 & 6750 & 9136 & 9330 \\
\hline & & 5634 & & 6871 & & 9529 & \\
\hline \multirow[t]{10}{*}{ SF paste } & 0.33 & 8467 & 8440 & 12016 & 12130 & 15963 & 16020 \\
\hline & & 8418 & & 12241 & & 16070 & \\
\hline & $0.33(25) *$ & 7692 & 7570 & 11095 & 10940 & 12224 & 12380 \\
\hline & & 7452 & & 10778 & & 12525 & \\
\hline & $0.33(30)$ & 6374 & 6450 & 9533 & 9480 & 11022 & 11150 \\
\hline & & 6524 & & 9431 & & 11268 & \\
\hline & 0.36 & 7900 & 7870 & 11031 & 10950 & 14893 & 15140 \\
\hline & & 7835 & & 10867 & & 15385 & \\
\hline & 0.39 & 6099 & 6200 & 9400 & 9330 & 13056 & 13150 \\
\hline & & 6306 & & 9265 & & 13243 & \\
\hline \multirow[t]{8}{*}{ NA mortar } & 0.30 & 8750 & 8830 & 10659 & 10600 & 11890 & 12050 \\
\hline & & 8903 & & 10542 & & 12210 & \\
\hline & 0.33 & 7708 & 7500 & 9400 & 9250 & 10977 & 10880 \\
\hline & & 7294 & & 9100 & & 10782 & \\
\hline & 0.36 & 6206 & 6350 & 7452 & 76920 & 10343 & 10440 \\
\hline & & 6500 & & 7931 & & 10545 & \\
\hline & 0.39 & 5701 & 5650 & 6517 & 6620 & 9744 & 9620 \\
\hline & & 5589 & & 6713 & & 9499 & \\
\hline \multirow[t]{8}{*}{ SP mortar } & 0.30 & 9077 & 9070 & 11174 & 10970 & 12385 & 12490 \\
\hline & & 9054 & & 10757 & & 12603 & \\
\hline & 0.33 & 7637 & 7630 & 9417 & 9530 & 11200 & 11090 \\
\hline & & 7614 & & 9639 & & 10969 & \\
\hline & 0.36 & 6781 & 6860 & 8249 & 8360 & 10478 & 10600 \\
\hline & & 6933 & & 8460 & & 10724 & \\
\hline & 0.39 & 6138 & 6090 & 7107 & 7030 & 9505 & 9530 \\
\hline & & 6050 & & 6950 & & 9548 & \\
\hline \multirow[t]{6}{*}{ SF mortar } & 0.33 & 6920 & 6940 & 10526 & 10330 & 11919 & 12130 \\
\hline & & 6984 & & 10132 & & 12336 & \\
\hline & 0,36 & 5930 & 6000 & 9140 & 8930 & 11717 & 11720 \\
\hline & & 6065 & & 8711 & & 11720 & \\
\hline & 0.39 & 4900 & 4970 & 7850 & 7830 & 10898 & 10710 \\
\hline & & 5030 & & 7805 & & 10526 & \\
\hline
\end{tabular}


APPENDIX A (CONTINUED)

\begin{tabular}{|c|c|c|c|c|c|c|c|}
\hline MATERIAL & $W / C^{*}$ & 3DAYS & AVERAGE & 7 DAYS & AVERAGE & 28 DAYS & AVERAGE \\
\hline \multirow[t]{4}{*}{ NA conc. } & 0.33 & 4950 & 5040 & 6304 & 6300 & 7412 & 7490 \\
\hline & & 5130 & & 6286 & & 7571 & \\
\hline & 0.39 & 4235 & 4150 & 4982 & 4850 & 6319 & 6300 \\
\hline & & 4056 & & 4711 & & 6285 & \\
\hline \multirow[t]{4}{*}{ SP conc. } & 0.33 & 5223 & 5330 & 6307 & 6330 & 7518 & 7380 \\
\hline & & 5441 & & 6355 & & 7232 & \\
\hline & 0.39 & 4396 & 4358 & 5066 & 5010 & 6391 & 6340 \\
\hline & & 4319 & & 4952 & & 6284 & \\
\hline \multirow[t]{8}{*}{ SF conc. } & 0.33 & 5010 & 4960 & 6244 & 6360 & 8088 & 8080 \\
\hline & & 4906 & & 6471 & & 8064 & \\
\hline & $0.33(25)$ & 5527 & 5510 & 7165 & 7170 & 8877 & 8990 \\
\hline & & 5496 & & 7175 & & 9102 & \\
\hline & $0.33(30)$ & 3658 & 3770 & 6522 & 6470 & 8101 & 8170 \\
\hline & & 3880 & & 6409 & & 8239 & \\
\hline & 0.39 & 3616 & 3670 & 4835 & 4920 & 6975 & 6830 \\
\hline & & 3730 & & 4997 & & 6682 & \\
\hline
\end{tabular}

C* --- cement pilus silica fume

()$^{* *} \ldots$ fl.oz / cwt of cementitious materiai 